\title{
Research On Equilibrium Strategy and Emergency Management of Three Oligarch Battery Manufacturers Under Cooperative Promotion and Low-Carbon Policy
}

\section{Bing Zhang}

Tianjin University

Meihong Zhu ( $\sim$ Mhzhu200831@126.Com )

Tianjin University College of Management and Economics

Li Zhao

Shandong jianzhu Univ.

Junhai Ma

Tianjin University

Tiantong Xu

Tianjin University

\section{Research Article}

Keywords: zinc-nickel battery, cooperative promotion, carbon trading, demand disturbance, complexity, bifurcation chaos

Posted Date: November 22nd, 2021

DOI: https://doi.org/10.21203/rs.3.rs-946577/v1

License: (c) (1) This work is licensed under a Creative Commons Attribution 4.0 International License.

Read Full License 


\section{Research on equilibrium strategy and emergency} management of three oligarch battery manufacturers under cooperative promotion and low-carbon policy

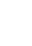

Bing Zhang, ${ }^{1}$ Meihong Zhu ${ }^{1,2}$, Li Zhao ${ }^{3}$, Junhai Ma ${ }^{1}$,Tiantong $\mathrm{Xu}^{1}$

1. College of Management and Economics, Tianjin University, Tianjin 300072, China

2. Zhejiang University Of Water Resources And Electric Power , Zhejiang 310018 China

3. Business school, Shandong Jianzhu University, Jinan 250101, China

4. Meihong Zhu E-Mail: Mhzhu200831@126.Com

5. Li Zhao E-Mail: 1zhao180828@126.com ;

Abstract:

As a crucial technology of solving energy shortage and environment contamination, battery technology is increasingly paid attention to by people. Among various batteries, lithium battery and Zinc-nickel battery are the most competitive and promising ones, especially the Zinc-nickel battery, which will induce shock to current battery industry chain. Meanwhile, the drastic change of exterior environment, such as 5G, Sharing Economy, low-carbon policy, trade protectionism and covid-19 has brought huge challenge to the management of battery industry chain. In this context, this paper set up a battery supply chain, including two zinc-nickel battery manufacturers and a lithium battery manufacturer. Against the background of cooperative promotion of big data and low-carbon policy, this paper constructs a cooperative game model under non cooperative game and demand disturbance respectively, analysing and discussing equilibrium strategy of supply chain. The results show that the price set by the manufacturer increases with the improvement of its technical level when consumers are more sensitive to technical level; with the increase of the Carbon Emission Technology Renewal Coefficient, the optimal price of all the three manufacturers will drop; when the market promotion rate is in the middle range, the price of zinc-nickel battery will be higher than that of lithium 
battery. In the demand disturbance model, the supply chain determines different optimal prices according to the different ranges of demand disturbance.

Keywords: zinc-nickel battery; cooperative promotion; carbon trading; demand disturbance; complexity; bifurcation chaos

\section{Introduction}

At present, energy shortage and environment contamination are difficulties that human beings have to face with. As the main body of energy consumption, fossil energy reserves are limited and nonrenewable. It is reported that the world's crude oil reserves can be exploited by human beings for less than 90 years, meanwhile, the other kinds of traditional energy, such as gas and coal, are also facing with a negative outlook. Worse still, the consumption and waste of energy are constantly increase, and the problem of energy supply is extremely serious. Based on this background, countries around the world have begun to change the energy composition structure around the concept of green security, high energy and sustainable development, and vigorously promote the development and research of new energy. The emergence of chemical power supply, especially battery, has become the focus of attention, and it has great advantages in energy and power density, efficiency and cost. Moreover, batteries have greatly influenced the lifestyle, communication, transportation and some other fields of modern people's life, applying widely wearable electronic devices, RFID devices, smart cards and electric vehicles. Recent years, the demand of batteries is constantly increasing. The battery will become one of the main energies in the future, and It is estimated that battery market will account for $40 \%$ of the total global energy by 2040 .

Among the existing batteries, lithium-ion batteries and zinc-nickel batteries are the power sources with strong competitiveness and development prospects. Rechargeable lithium battery derives from the concept of solid solution electrode and rocking chair battery proposed in the 1970s. Nowadays, lithium-ion battery has become one of the most widely used power sources for many energy storage devices (such as wearable 
electronic devices, electric and hybrid vehicles and fixed purpose devices). However, the shortage of lithium and cobalt has brought huge challenge to mass production of lithium batteries. Also, the development of lithium-ion battery has reached the upper limit of technical level. Under such limitation, People turn their attention to a new type of high-energy power supply with high energy density, green, safe and sustainable development to replace lithium-ion batteries for energy conversion and energy storage. As a kind of alkaline cell, zinc-nickel batteries have been widely applied in electronic components, fixed power supply and other fields. It has the advantages of low cost, high discharge voltage and energy density, large discharge current, green environmental protection and so on.

Although zinc-nickel batteries have a promising future, lithium batteries still occupy a dominant position in the industrial pattern. There is a long way to go for zinc-nickel battery to give full play to its advantages, expand its market share and occupy a place, in which the remodeling and management and the game strategies of different manufacturers are of crucial importance, especially under the background of the drastic change of exterior environment, such as 5G, Sharing Economy, low-carbon policy, trade protectionism and covid-19. How to make good use of the external environment, give play to their own advantages, avoid risks and obtain advantages in the competition will become an important factor for the development of zinc-nickel battery.

In addition, with the vigorous development of mobile Internet, the task of product promotion has gradually shifted from retailers to third-party platforms or institutions. For example, the e-commerce platform not only provides consumers with product information, but also provides businesses with advertising promotion and other services, just as domestic communication giants can provide cooperative businesses with advertising promotion services in the form of SMS push. Through accurate website and SMS push, we can deeply tap the target users, further explore the potential market demand, and improve the market demand and competitiveness of this 
product. How to make good use of this promotion service in the competition will also become the top priority in the development of zinc nickel battery as a latecomer.

This paper will build the basic model of three oligarchs' non cooperative game under the background of product promotion and three oligarchs' cooperative game model under demand fluctuation. This paper focuses on the following questions:

(1) What is the equilibrium strategy of the three oligarchs game in the basic model?

(2) How will the cooperative promotion model affect the equilibrium strategy of battery manufacturers?

(3) What will happen to the equilibrium strategy of three oligarchs cooperation under different demand fluctuations?

\section{Literature Review}

The zinc-nickel battery studied in this paper has the advantages of low-cost, high power density and environmental-friendly and is considered to be one of the most potential electric vehicle batteries. Recent years, researches on zinc-nickel battery have never halted, and breakthrough achievements have also been made. For instance, Meng et al. (2019) has succeeded in growing Zn Al LDHs / HC on hollow carbon spheres, showing large specific surface area and good mechanical stability, facilitating the deposition and growth of zinc, and the core-shell structure is beneficial to electrolyte diffusion. Meanwhile, the material takes hollow carbon spheres as the conductive substrate, organizes and forms a developed conductive network structure, and establishes an efficient and stable path for electron transport successfully. Chen and others designed 3D $\mathrm{ZnO}-\mathrm{Cu}-\mathrm{C}$ hybrid microspheres. There is copper decorating on the surface and internal in-situ carbon, forming a 3D penetrating conductive frame as the path for electron transport, and the external copper can also restrain the dissolution of active ingredients effectively. Such structure provides with large effective surface area, promoting the quick move of ions. Chen et al. (2019) prepared gel precursors, and then prepared carbon-coated nano $\mathrm{ZnO}$ by heat treatment. The 
nano $\mathrm{ZnO}$ is combined with carbon physical cover, maintaining the efficient utilization of nano $\mathrm{ZnO}$, and also preventing the dendritic growth and densification of anode, showing high electrochemical activity, low resistance and high discharge capacity of 622 mAhg-1. Cui et al. (2018) prepared graphene / ZnO by physical method. In the process of charging and discharging, graphene cut $\mathrm{Zn}$ in situ and anchored zinc atoms, which effectively inhibited the dissolution of zinc oxide in alkaline solution. In addition, carbon nanotube coated zinc oxide was also synthesized (Cui et al. 2019). In this way, the reaction of zinc oxide with alkali liquor was prevented effectively.

There are some scholars who have taken cooperative promotion into consideration in the research on supply chain. Huang and Li (2001) studied the optimal advertising strategy of cooperative advertising between manufacturers and agents in the supply chain by applying the method of game theory; Zhou et al. (2018) studied the optimal cooperative advertising and ordering strategy of a two-level supply chain based on risk aversion preference. Chutani and Sethi (2018) analyzed the optimal advertising decision-making problem of closed-loop supply chain when only one member of the supply chain invested in advertising. Lin and Shao (2014) studied the investment strategy of online advertising under the Internet environment. Karray (2015) studied two cooperative promotion strategies in Supply Chain Based on game theory. Karray et al. (2017) studied the cooperation effect of two competitive manufacturers and one retailer. Xie et al. (2017) studied the coordination contract considering cooperative advertising in dual channel closed-loop supply chain.

In terms of carbon quota and carbon trading, Ji et al. (2017) studied the O2O retailing supply chain in low-carbon environment, and set up three models including unlimited carbon trading, grandfather carbon trading and benchmarking carbon trading. Research shows that benchmarking can effectively promote manufacturers to produce low-carbon products. Under the policy of quota and carbon trading, Xu et al. (2016) considered consumers' preference and manufacturer's carbon emission reduction, set up the centralized decision-making and decentralized decision-making models, and 
coordinated the supply chain with wholesale price contract, cost sharing contract and two-part pricing contract. Yang et al. (2017) built two competitive supply chain in the context of carbon cap Trading, and explored the impact of its horizontal cooperation and vertical cooperation on carbon emission reduction. Li et al. (2018) considered the game model of carbon emission benchmark for government decision-making, analyzing how the manufactures' production decisions change with the change of government carbon trading policy under consumers' carbon preference and technology upgrading. Wang et al. (2018) proposed a mechanism which considers carbon trading of fresh food supply chain and cold chain logistics services. Different from previous researches, this one studied the carbon trading behaviors within the supply chain, revealing the relationship between carbon trading and logistic service and its influence on the cooperation between suppliers and retailers. Qian et al. (2020) considered retailers' equity concerns, in the context of carbon trading, set up the wholesale price contract and two pricing contracts, and the supply chain coordination is realized through the bargaining model. Results show that the intensification of equity issues will reduce the carbon emission reduction level of manufacturers. Ji et al. (2020) studied the impact of the inverse relationship between carbon trading price and carbon quota on supply chain production decision, deduced the optimal carbon quota under wholesale price contract and income sharing contract, and found that the social welfare performance of the two contracts is different under different environmental concern parameters.

The problem of supply chain risk has been widely concerned by academia for a long time. Kleindorfer and Saad (2005) believe that the risks affecting the operation and management of the supply chain are mainly divided into two types, namely, the risk caused by the uncoordinated supply and demand and the risk caused by the disruption of normal operation by emergencies. While as for emergence risk in supply chain, Chopra and Sodhi (2004) pointed out that because of the characteristics of low occurrence probability and low predictability, emergencies are often ignored in practice and research. Emergency management in response to supply chain 
emergencies includes a variety of research directions, and Disturbance management, which is closely related to the research focus of this paper, was first proposed by Clausen et al. (2010). On the research of supply chain emergency disturbance management, the existing literature has studied from different supply chain modes, disturbance factors, emergency coordination mechanism and so on. Xiao et al. (2007) studied the decision-making of the supply chain composed of one manufacturer and two retailers after the sudden change of demand caused by emergencies, and pointed out that the supply chain coordination after the production deviation cost can be realized by adjusting the quantity discount contract. Zhang et al. (2012) analyzed the coordination problem of multi retailer competition in supply chain under demand disturbance, and proposed that emergency coordination can be carried out through revenue sharing contract. Ma and Xie (2016) took the duopoly air conditioning market under demand disturbance as the research object, and analyzes the impact of disturbance on dynamic game system. Xie et al. (2021) studied a two echelon supply chain composed of buyers and sellers and buyers. Considering the buyer's uncertain demand and income, the repurchase contract in supply chain is studied, and the effects of income uncertainty and relative bargaining power on the performance of repurchase contract are studied.

In the end, researches in this paper are related to the research on evolutionary game of supply chain in complex system. In actual economic activities, due to complex environment, it is difficult for supply chain members to make completely rational decisions, while the nonlinear system dynamics model can be used to study the process of dynamic game. Chen and $\mathrm{Hu}$ (2018) constructed a dynamic evolutionary game model of government and manufacturer time based on carbon tax and subsidy, and analyzed the game behavior between manufacturer and government under dynamic and static carbon emission reduction policies. Tong et al. (2019) considered the carbon trading policy and consumers' low-carbon preference, constructed the retailer led Stackelberg game, and studied the equilibrium solution and stability of the evolutionary game. Zhang et al. (2019) constructed an evolutionary game model 
between the government and manufacturers under the background of carbon quota and carbon trading, and studied the impact of government policies on the carbon trading market under the conditions of static carbon trading price and dynamic carbon trading price. The results show that when the government implements the static carbon trading price, the evolutionary game can not achieve stability. Under the dynamic carbon trading price, there is a stable strategy. In the multi-channel recycling supply chain of duopoly manufacturers, Zhan et al. (2019) explored the impact of carbon tax on manufacturers' recycling and carbon emission reduction strategies, further constructed a multi cycle dynamic game model, and analyzed the complex characteristics of bifurcation, chaos and sensitivity. Bao et al. (2020) considered the government subsidy behavior and consumers' low-carbon preference factors, studied the short-term and long-term game behavior of duopoly carmakers, and compared the optimal strategies under three game models (cooperation, noncooperation and cost sharing). Ma and $\mathrm{Wu}$ (2014) constructed a supply chain including strategic consumers, the government and two manufacturers producing electric vehicles and fuel vehicles respectively, and analyzed how subsidies and carbon emission constraints affect the operation of the supply chain on the basis of evolutionary game. Gao and Ma (2009) studied the complex dynamic behavior of a financial system. Through numerical simulation, the path of singular non chaotic attractor is found, the time-delay feedback system is considered, and the stability and Hopf bifurcation of the controlled system are studied. Xu and Ma (2021) established a solar photovoltaic supply chain including the government, utility grid, exclusive solar panel retailers and households. The long-term equilibrium strategy of nonlinear dynamic system is studied, and how the stability of equilibrium, conservative and aggressive strategies affect the system are studied. Ma et al. (2020) studied the supply chain system composed of electric vehicles and fuel vehicles under policy intervention, and analyzed and revealed the impact of government subsidies and carbon emission constraints on the operation of the supply chain system under different pricing time sequences. Ma and Xie (2016) studied a dual channel supply chain including a single manufacturer and retailer, considering that the manufacturer has symmetrical or asymmetric channel attributes. 
Ma and Sun (2017a); Lou and Ma (2018); Ma and Sun (2017b) established a mixed game model containing four oligarchs, studied the complexity of the system and the influence of parameters on the stability of the system (Zhu et al. 2021).

\section{Methodology}

\subsection{Basic model}

Here, we consider a market structure in which there are competitions between two zinc-nickel battery manufacturers and one lithium battery manufacturer. We assume that all of them are able to adopt price competition strategy. Besides, zinc-nickel battery manufacturers cooperate with China Mobile and other communication companies, in order to expand their market influence. Here, we set the subscript 1 to represent the lithium battery enterprise, referred to as lithium battery; Subscripts 2 and 3 indicate zinc nickel battery enterprises cooperating with China Mobile.

Impacted by technology barrier, different manufacturers often take the form of non-technical cooperation in the competitive game. Among the three manufacturers, we set the actual technical level of lithium battery as $l_{1}$, zinc-nickel No. 1 battery as $l_{2}$ and zinc-nickel No. 2 battery as $l_{3}$. Battery manufacturers can gain higher technology level by more investment, so the technology update function is as follows:

$$
\left\{\begin{array}{l}
l_{1}^{N}=l_{L}+\tau \operatorname{In}\left(C_{I 1}+1\right) \\
l_{2}=l_{Z N}+\tau \operatorname{In}\left(C_{I 2}+1\right) \\
l_{3}=l_{Z N}+\tau \operatorname{In}\left(C_{I 3}+1\right)
\end{array}\right.
$$

In formula (1), We set the basic battery level of lithium battery manufacturers when building the plant as ${ }^{l}$, and the basic battery level of both Zn Ni batteries is ${ }{ }_{Z N}$, and $l_{Z N} \geq l_{L} . \quad C_{I i}(i=1,2,3)$ is the investment capital in the technology of battery manufacturers. Here, we assume that the technology capital conversion rate of all enterprises is the same, set as $\tau$, and $\tau>0$. It is not difficult to see that the higher the capital invested, the higher the technical level of capital conversion. 
In battery market, we set the total market demand is a. Due to consumers' preference for zinc-nickel battery is different, we set it as $\theta$, while the preference for lithium battery is set as $1-2 \theta$. The manufacturer's battery price is set as $p_{i}^{N}(i=1,2,3)$, so that manufacturers' demand function is shown below, and $q_{i}^{N}(i=1,2,3)$ represents the market sales volume of each manufacturer:

$$
\left\{\begin{array}{l}
q_{1}^{N}=(1-(2 \theta+\rho)) a-\alpha_{1} p_{1}^{N}+\alpha_{2} l_{1}^{N}-\beta\left(p_{1}^{N}-\left(p_{2}^{N}+p_{3}^{N}\right)\right) \\
q_{2}^{N}=(\theta+\sigma \rho) a-\alpha_{1} p_{2}^{N}+\alpha_{2} l_{2}-\beta\left(p_{2}^{N}-\left(p_{1}^{N}+p_{3}^{N}\right)\right) \\
q_{3}^{N}=(\theta+(1-\sigma) \rho) a-\alpha_{1} p_{3}^{N}+\alpha_{2} l_{3}-\beta\left(p_{3}^{N}-\left(p_{1}^{N}+p_{2}^{N}\right)\right)
\end{array}\right.
$$

In formula (2), parameter $\rho$ represents the market promotion rate of the two zinc-nickel manufacturers after they cooperate with China Mobile, and $\sigma$ represents the promotion degree of zinc-nickel No. 1 battery manufacturer. Since the consumers can see the price of battery manufacturers intuitively, the price has a great influence on sales, and we set the influence coefficient of battery price on sales as $\alpha_{1}$. Meanwhile, the technology quality of the battery influences its life directly, so the batteries which can be used longer attracts more consumers, and in turn let the influence coefficient of battery technology on sales be $\alpha_{2}$. Moreover, different prices would also lead to consumption transfer of consumers in the market, which results in cross change of sales volume in price competition, and here we set the sales cross coefficient of the three batteries due to price as $\beta$.

In the marketing process, battery costs vary from manufacturer to manufacturer, we set it as $c_{i}(i=1,2,3)$. In order to encourage the manufacturers to improve quality and service efficiency, prolong the service life, governments will offer subsidy according to their technology, and the subsidy rate is $r$.Besides, in order to deal with global climate issues, governments often adopt a series of carbon limitation policy, restrict the carbon emission of the enterprises. Accordingly, we set the carbon limit given by 
290 the government to enterprises as $E$, and the basic unit carbon emission of each

291 lithium battery is $e_{L}$, and that of zinc nickel battery is $e_{Z N}$, and the unit carbon price 292 is set as $p_{e}$. Meanwhile, improvement on technology can enhance the green degree 293 of battery production and reduce carbon emission to some extent, so we set it as the 294 carbon emission technology renewal coefficient $\gamma$. Due to the cooperation between

295

$$
\begin{aligned}
& \frac{\partial \pi_{3}^{N}}{\partial p_{3}^{N}}=-e_{z} p_{e}\left(-\alpha_{1}-\beta\right)\left(1-l_{3} \gamma\right)+\left(-c_{3}+p_{3}^{N}\right)\left(-\alpha_{1}-\beta\right)(1-\varepsilon \rho(1-\sigma)) \\
& +\left(-p_{3}^{N} \alpha_{1}+l_{3} \alpha_{2}-\left(-p_{1}^{N}-p_{2}^{N}+p_{3}^{N}\right) \beta+a(\theta+\rho(1-\sigma))\right)(1-\varepsilon \rho(1-\sigma))
\end{aligned}
$$

By deriving the above formula (4) (5) (6), the price equilibrium strategy can be 
obtained as follows:

$$
\left\{\begin{array}{l}
p_{1}^{N}=\left(\begin{array}{l}
A B\left(2 F^{2} G+2 F l_{1}^{N} \alpha_{2}+c_{3} F \beta+l_{3} \alpha_{2} \beta\right)+B e_{z} F p_{e} \beta\left(1-l_{3} \gamma\right) \\
-a A B\left(\begin{array}{l}
\beta-4 \beta \theta-2 \beta \rho+ \\
2 F(-1+2 \theta+\rho)
\end{array}\right)+A \beta\left(\begin{array}{l}
c_{2} F(-1+\varepsilon \rho \sigma)-\left(l_{1}^{N}-l_{2}\right) \alpha_{2}(-1+\varepsilon \rho \sigma)+ \\
F\left(G+e_{z} p_{e}\left(-1+l_{2} \gamma\right)-G \varepsilon \rho \sigma\right.
\end{array}\right)
\end{array}\right),\left(\begin{array}{l}
2 \alpha_{1}\left(2 \alpha_{1}+3 \beta\right) \\
(-1+A \varepsilon \rho \sigma)
\end{array}\right) \\
p_{2}^{N}=\frac{1}{2 A B \alpha_{1}\left(2 \alpha_{1}+3 \beta\right)}\left(\begin{array}{l}
c_{2} F H\left(2 \alpha_{1}+\beta\right)+H\left(\begin{array}{l}
a \beta+F\left(c_{3}+G\right) \beta+\left(l_{1}^{N}+l_{3}\right) \alpha_{2} \beta+ \\
l_{2} \alpha_{2}\left(2 \alpha_{1}+\beta\right)+2 a \alpha_{1}(\theta+\rho \sigma)
\end{array}\right) \\
+e_{z} F p_{e}\left(2 A \alpha_{1}\left(-1+l_{2} \gamma\right)+J\right)
\end{array}\right) \\
p_{3}^{N}=\frac{1}{2 A B \alpha_{1}\left(2 \alpha_{1}+3 \beta\right)}\left(\begin{array}{l}
c_{3} F H\left(2 \alpha_{1}+\beta\right)+e_{z} F p_{e}\left(J-2 B \alpha_{1}\left(-1+l_{3} \gamma\right)\right)+ \\
H\left(\begin{array}{l}
a \beta+F\left(c_{2}+G\right) \beta+\left(l_{1}^{N}+l_{2}\right) \alpha_{2} \beta+ \\
l_{3} \alpha_{2}\left(2 \alpha_{1}+\beta\right)+2 a \alpha_{1}(\theta+\rho-\rho \sigma)
\end{array}\right)
\end{array}\right)
\end{array}\right.
$$

$$
\begin{aligned}
& A=1+\varepsilon \rho(-1+\sigma) ; B=-1+\varepsilon \rho \sigma ; H=(-1+\varepsilon \rho(1+\varepsilon \rho(-1+\sigma) \sigma)) ; F=\alpha_{1}+\beta \\
& G=c_{1}+e_{l} p_{e}\left(1-l_{1}^{N} \gamma\right) ; J=\beta\left(-2+\varepsilon \rho+\gamma\left(l_{2}+l_{3}+l_{2} \varepsilon \rho(-1+\sigma)-l_{3} \varepsilon \rho \sigma\right)\right)
\end{aligned}
$$

\subsubsection{Model analysis}

Lemma 1: As for lithium manufacturers, when $\alpha_{2}>e_{l} p_{e}\left(\alpha_{1}+\beta\right) \gamma, p_{1}^{N}$ increases

317 with the increase of $l_{1}^{N}$, otherwise, it decreases; For zinc-nickel battery 318 manufacturers who promote cooperation, when $\alpha_{2}>\frac{e_{z} p_{e}\left(\alpha_{1}+\beta\right) \gamma}{1-\varepsilon \rho \sigma}, p_{2}^{N}$ increases 319 with the increase of ${ }^{l_{2}}$, otherwise, it decreases; For zinc-nickel battery manufacturers 320 who don't promote cooperation, when $\alpha_{2}>\frac{e_{z} p_{e}\left(\alpha_{1}+\beta\right) \gamma}{1-\varepsilon \rho+\varepsilon \rho \sigma}, p_{3}^{N}$ increases with the 321 increase of ${ }^{l_{3}}$, otherwise, it decreases.

Prove:

324 The following formula can be obtained by deriving $l_{1}^{N}$ from $p_{1}^{N}$ in formula (7):

$$
-\frac{\left(2 \alpha_{1}+\beta\right)\left(-\alpha_{2}+e_{l} p_{e}\left(\alpha_{1}+\beta\right) \gamma\right)}{2 \alpha_{1}\left(2 \alpha_{1}+3 \beta\right)}
$$

326 It is easy to get that the denominator is positive. In the numerator, when 
$\alpha_{2}>e_{l} p_{e}\left(\alpha_{1}+\beta\right) \gamma$, the original formula is greater than 0 , namely, $p_{1}^{N}$ increases

328 with the increase of $l_{1}^{N}$, otherwise, it decreases.

330 The following formula can be obtained by deriving $l_{2}$ from $p_{2}^{N}$ in formula (7):

$$
\frac{\left(2 \alpha_{1}+\beta\right)\left(e_{z} p_{e}\left(\alpha_{1}+\beta\right) \gamma+\alpha_{2}(-1+\varepsilon \rho \sigma)\right)}{2 \alpha_{1}\left(2 \alpha_{1}+3 \beta\right)(-1+\varepsilon \rho \sigma)}
$$

$\varepsilon, \rho, \sigma$ are all greater than 0 and less than 1 , so $-1+\varepsilon \rho \sigma<0$, and therefore

denominator is less than 0 , and $\alpha_{2}$ is negative. Namely, when $\alpha_{2}>\frac{e_{z} p_{e}\left(\alpha_{1}+\beta\right) \gamma}{1-\varepsilon \rho \sigma}$, $p_{2}^{N}$ increases with the increase of $l_{2}$, otherwise, it decreases.

The following formula can be obtained by deriving $l_{3}$ from $p_{3}^{N}$ in formula (7):

$$
-\frac{\left(2 \alpha_{1}+\beta\right)\left(e_{z} p_{e}\left(\alpha_{1}+\beta\right) \gamma+\alpha_{2}(-1+\varepsilon(\rho-\rho \sigma))\right)}{2 \alpha_{1}\left(2 \alpha_{1}+3 \beta\right)(1+\varepsilon \rho(-1+\sigma))}
$$

$$
\alpha_{2}>\frac{e_{z} p_{e}\left(\alpha_{1}+\beta\right) \gamma}{1-\varepsilon \rho+\varepsilon \rho \sigma}
$$

$p_{3}^{N}$ increases with the increase of ${ }^{l_{3}}$, otherwise, it decreases.

Lemma 1 gives the relationship among different manufacturers' technical level, the impact of technology on sales and the optimal price. It can be seen that for every battery manufacturer, when technology has a great impact on sales, or consumers are more sensitive to the technical level, the price set by the manufacturer increases with the improvement of its technical level. However, when the impact of technology on sales is small, or consumers are less sensitive to the technical level, the price set by manufacturers decreases with the improvement of their technical level. Therefore, in order to realize the positive incentive of technology level to price, we should actively publicize and cultivate consumers' sensitivity to technology level. 
351 Lemma 2: $\frac{\partial p_{1}^{N}}{\partial \theta}<0, \frac{\partial p_{2}^{N}}{\partial \theta}>0, \frac{\partial p_{3}^{N}}{\partial \theta}>0 ; \frac{\partial p_{1}^{N}}{\partial \gamma}<0, \frac{\partial p_{2}^{N}}{\partial \gamma}<0, \frac{\partial p_{3}^{N}}{\partial \gamma}<0$.

Prove:

354 Let $p_{1}^{N}, p_{2}^{N}$ and $p_{3}^{N}$ in formula (7) take a deviation of $\theta$ and get:

355

$\frac{\partial p_{1}^{N}}{\partial \theta}=-\frac{2 a}{2 \alpha_{1}+3 \beta}>0 \frac{\partial p_{2}^{N}}{\partial \theta}=\frac{\partial p_{3}^{N}}{\partial \theta}=\frac{a}{2 \alpha_{1}+3 \beta}>0$

, lemma 2 is proved.

356 Let $p_{1}^{N}, p_{2}^{N}$ and $p_{3}^{N}$ in formula (7) take a deviation of $\gamma$ and get:

357

$$
\begin{aligned}
& \frac{\partial p_{1}^{N}}{\partial \gamma}=\left(p_{e}\left(\alpha_{1}+\beta\right)\left(e_{z} \beta\left(l_{2}+l_{3}+l_{2} \varepsilon \rho(-1+\sigma)-l_{3} \varepsilon \rho \sigma\right)-e_{l} l_{1}\left(2 \alpha_{1}+\beta\right)\left(-1+\varepsilon \rho+\varepsilon^{2} \rho^{2}(-1+\sigma) \sigma\right)\right)\right) / \\
& \left(2 \alpha_{1}\left(2 \alpha_{1}+3 \beta\right)(-1+\varepsilon \rho(1+\varepsilon \rho(-1+\sigma) \sigma))\right)
\end{aligned}
$$

358

359 The denominator is less than zero. In the numerator, $l_{3}-l_{3} \varepsilon \rho \sigma>0$ and 360 $l_{2}+l_{2} \varepsilon \rho(-1+\sigma)>0$ can be easily gotten, namely,

$-e_{l} l_{1}\left(2 \alpha_{1}+\beta\right)\left(-1+\varepsilon \rho+\varepsilon^{2} \rho^{2}(-1+\sigma) \sigma\right)>0 \quad, \quad$ so $\quad$ we can get $\frac{\partial p_{1}^{N}}{\partial \gamma}<0$, $\frac{\partial p_{2}^{N}}{\partial \gamma}=\frac{p_{e}\left(\alpha_{1}+\beta\right)\left(e_{l} l_{1} \beta\left(1-\varepsilon \rho-\varepsilon^{2} \rho^{2}(-1+\sigma) \sigma\right)+e_{z}\left(l_{2}\left(2 \alpha_{1}+\beta\right)(1+\varepsilon \rho(-1+\sigma))+l_{3} \beta(1-\varepsilon \rho \sigma)\right)\right)}{2 \alpha_{1}\left(2 \alpha_{1}+3 \beta\right)(1+\varepsilon \rho(-1+\sigma))(-1+\varepsilon \rho \sigma)}$,

$\frac{\partial p_{3}^{N}}{\partial \gamma}=-\frac{p_{e}\left(\alpha_{1}+\beta\right)\left(e_{l} l_{1} \beta\left(-1+\varepsilon \rho+\varepsilon^{2} \rho^{2}(-1+\sigma) \sigma\right)+e_{z}\left(l_{2} \beta(-1+\varepsilon \rho-\varepsilon \rho \sigma)+l_{3}\left(2 \alpha_{1}+\beta\right)(-1+\varepsilon \rho \sigma)\right)\right)}{2 \alpha_{1}\left(2 \alpha_{1}+3 \beta\right)(1+\varepsilon \rho(-1+\sigma))(-1+\varepsilon \rho \sigma)}$

Similarly, $\frac{\partial p_{2}^{N}}{\partial \gamma}<0 \frac{\partial p_{3}^{N}}{\partial \gamma}<0$

can easily gotten from two formulas above.

According to lemma 2, the greater the consumer preference for zinc nickel battery, the higher the price of zinc nickel battery and the lower the price of lithium battery. With the increase of carbon emission technology renewal coefficient, the optimal prices of the three battery manufacturers will decline. Due to the improvement of emission 
Prove:

$$
\rho_{1}=\frac{1}{2 a \varepsilon \sigma(1+\sigma)}\left(a+\left(\left(l_{1}-l_{2}\right) \alpha_{2}+\left(\alpha_{1}+\beta\right)\left(c_{1}-c_{2}+e_{l} p_{e}\left(1-l_{1}^{N} \gamma\right)\right)\right) \varepsilon \sigma+a(1+\varepsilon-3 \varepsilon \theta) \sigma-M_{1}\right)
$$

$$
\rho_{2}=\frac{1}{2 a \varepsilon \sigma(1+\sigma)}\left(a+\left(\left(l_{1}-l_{2}\right) \alpha_{2}+\left(\alpha_{1}+\beta\right)\left(c_{1}-c_{2}+e_{l} p_{e}\left(1-l_{1}^{N} \gamma\right)\right)\right) \varepsilon \sigma+a(1+\varepsilon-3 \varepsilon \theta) \sigma+M_{1}\right)
$$

$$
M_{1}=\sqrt{\begin{array}{l}
4 a \varepsilon\left(\left(-l_{1}^{N}+l_{2}\right) \alpha_{2}-\left(\alpha_{1}+\beta\right)\left(c_{1}-c_{2}+p e\left(e_{l}-e_{z}-e_{l} l_{1}^{N} \gamma+e_{z} l_{2} \gamma\right)\right)+a(-1+3 \theta)\right) \sigma(1+\sigma) \\
+\left(a+\left(\left(l_{1}^{N}-l_{2}\right) \alpha_{2}+\left(\alpha_{1}+\beta\right)\left(c_{1}-c_{2}+e_{l} p_{e}-e_{l} l_{1}^{N} p_{e} \gamma\right)\right) \varepsilon \sigma+a(1+\varepsilon-3 \varepsilon \theta) \sigma\right)^{2}
\end{array}}
$$

$$
\rho_{3}=\frac{1}{2 a \varepsilon(-2+\sigma)(-1+\sigma)}(a(2+\varepsilon(-1+3 \theta)(-1+\sigma)-\sigma)-
$$$$
\left.\left(\left(l_{1}^{N}-l_{3}\right) \alpha_{2}+\left(\alpha_{1}+\beta\right)\left(c_{1}-c_{3}+e_{l} p_{e}\left(1-l_{1}^{N} \gamma\right)\right)\right) \varepsilon(-1+\sigma)-M_{2}\right)
$$

$$
\rho_{4}=\frac{1}{2 a \varepsilon(-2+\sigma)(-1+\sigma)}(a(2+\varepsilon(-1+3 \theta)(-1+\sigma)-\sigma)-
$$

$$
\left.\left(\left(l_{1}^{N}-l_{3}\right) \alpha_{2}+\left(\alpha_{1}+\beta\right)\left(c_{1}-c_{3}+e_{l} p_{e}\left(1-l_{1}^{N} \gamma\right)\right)\right) \varepsilon(-1+\sigma)+M_{2}\right)
$$

$$
M_{2}=\sqrt{\left(\begin{array}{l}
-4 a \varepsilon\left(a+\left(l_{1}^{N}-l_{3}\right) \alpha_{2}+\left(\alpha_{1}+\beta\right)\left(c_{1}-c_{3}+p_{e}\left(e_{l}-e_{z}-e_{l} l_{1}^{N} \gamma+e_{z} l_{3} \gamma\right)\right)-3 a \theta\right) \\
(-2+\sigma)(-1+\sigma)+\left(\begin{array}{l}
\left.\left(\left(l_{1}^{N}-l_{3}\right) \alpha_{2}+\left(\alpha_{1}+\beta\right)\left(c_{1}-c_{3}+e_{l} p_{e}-e_{l} l_{1}^{N} p_{e} \gamma\right)\right) \varepsilon(-1+\sigma)+\right)^{2} \\
a(-2+\sigma+\varepsilon(-1+3 \theta+\sigma-3 \theta \sigma))
\end{array}\right)
\end{array}\right)}
$$




$$
p_{1}^{N}-p_{2}^{N}=\left(\begin{array}{l}
\left(l_{1}^{N}-l_{3}\right) \alpha_{2}+\left(\alpha_{1}+\beta\right)\left(c_{1}-c_{3}+p_{e}\left(e_{l}-e_{z}-e_{l} l_{1}^{N} \gamma+e_{z} l_{3} \gamma\right)\right) \\
+a(1-3 \theta+\rho(-2+\sigma))(1+\varepsilon \rho(-1+\sigma)) \\
+\left(\left(l_{1}^{N}-l_{3}\right) \alpha_{2}+\left(\alpha_{1}+\beta\right)\left(c_{1}-c_{3}+e_{l} p_{e}\left(1-l_{1}^{N} \gamma\right)\right)\right) \varepsilon \rho(-1+\sigma)
\end{array}\right) /\left(2 \alpha_{1}+3 \beta\right)(1+\varepsilon \rho(-1+\sigma))
$$

392 It is easy to get that the numerator of $p_{1}^{N}-p_{2}^{N}$ is a quadratic function about market 393 promotion rate, and $a \varepsilon\left(-\sigma-\sigma^{2}\right)$, the quadratic term coefficient is negative, while 394 the denominator of $p_{1}^{N}-p_{2}^{N},\left(2 \alpha_{1}+3 \beta\right)(-1+\varepsilon \rho \sigma)$,is always negative. As a result, 395 it is a quadratic function with the opening upward for the numerator. Therefore, we 396 can draw the conclusion that when the market promotion rate is in the range between 397 two solutions, $p_{1}^{N}<p_{2}^{N}$. If the difference is zero, we can get $\rho_{1}$ and $\rho_{2}$. Similarly, 398 we can analyze the contrast between $p_{1}^{N}$ and $p_{3}^{N}$. 399

400 401 402

Lemma 3 gives the influence of market promotion rate on the price comparison of lithium battery and zinc nickel battery. When the market promotion rate is in the middle range, the price of zinc nickel battery will be higher than that of lithium battery, and a higher or lower market promotion rate will reduce the market competitiveness of zinc nickel battery. Therefore, an appropriate degree of market promotion should be selected.

\subsubsection{Numerical simulation}

Since the profit expression after bringing in the equilibrium price is too difficult, and is hard to analyze, here, it'll be analyzed by numerical simulation. First, according to previous value of related research, assign the following values to the relevant parameters:

$$
\begin{aligned}
& a=10, \theta=0.2, \sigma=0.3, \alpha_{1}=0.5, \alpha_{2}=0.5, \beta=0.3, c_{1}=0.1, c_{2}=0.1, c_{3}=0.1, \\
& C_{1}=1, C_{2}=2, C_{3}=3, r=0.1, e_{l}=1.2, e_{z}=1.1, p_{e}=2, e=1, \rho=0.1, \varepsilon=0.1, \\
& \tau=0.3, l_{L}=1, l_{Z N}=1.2, \gamma=0.2
\end{aligned}
$$


414 Market promotion rate

415 The influence the market promoting rate have on battery manufacturers' profit under 416 different promotion extent is shown in Figure 1. It can be seen that the profit of 417 zinc-nickel battery manufacturers increases with the promotion of market promoting 418 rate, while that of the lithium battery manufacturers is the opposite. Meanwhile, under 419 different promotion extent, the impacts of market promoting rate on profit are 420 different. That is, the higher the promotion degree of zinc-nickel battery 421 manufacturers, the greater the impact of market promotion rate on them. Conclusion 422 above shows that zinc-nickel battery manufacturers are supposed to enhance the 423 cooperation with China Mobile, improving the market promoting rate, to boost profits. 424 Moreover, they should also improve promoting extent, in order to gain more 425 advantages in the competition of zinc-nickel battery.
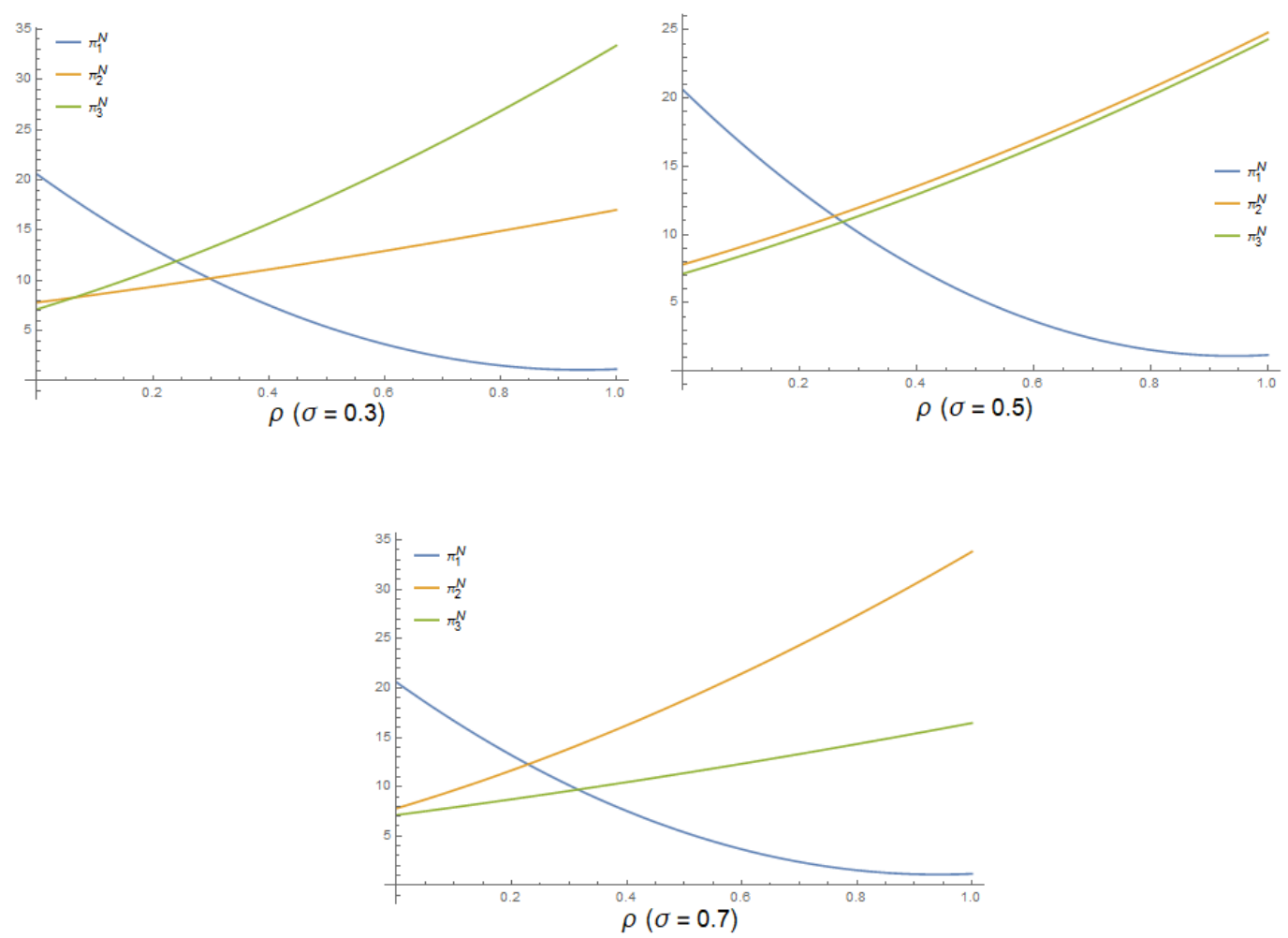
different promotion degrees 
431 The impact of market promotion rate on the profits of battery manufacturers under 432 different promotion rates is shown in Figure 2. It can be seen that although the profit 433 of zinc-nickel battery is increasing with the improvement of market promotion rate, 434 the profit of zinc-nickel battery manufacturers will be affected if the rate of 435 cooperative promotion continues to increase. Comparing the three pictures, the rate of 436 cooperative promotion has a greater impact on zinc-nickel battery manufacturer 3

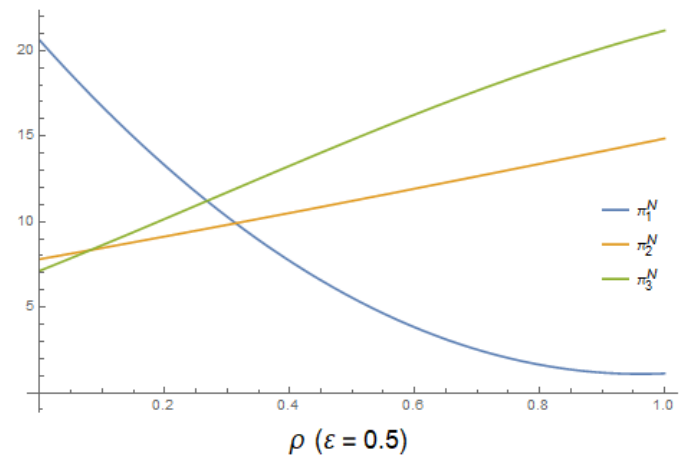

441 than zinc-nickel battery manufacturer 2 . Thus, it can be seen, zinc-nickel battery manufacturers should control the corresponding cooperation rate to avoid affecting their own profits.
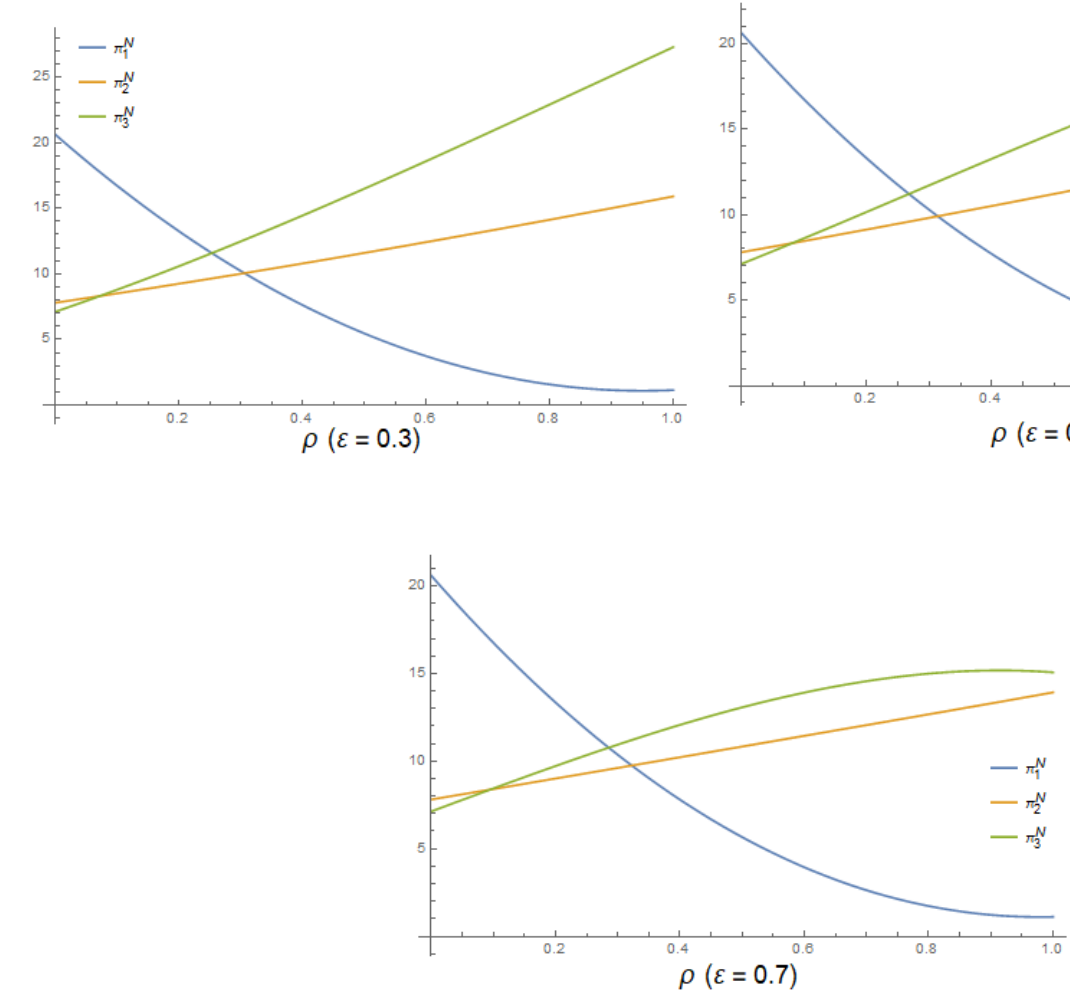

Fig. 2 impact of market promotion rate on battery manufacturer's profit under different promotion rates

Carbon emission reduction technology renewal coefficient

The impact of carbon emission reduction technology renewal coefficient on the profits of battery manufacturers under different unit carbon prices is shown in Figure 3. It can be seen that with the increase of carbon emission reduction technology 
renewal coefficient, the profits of the three battery manufacturers are increasing. At the same time, with the increase of unit carbon price, the renewal coefficient of carbon emission reduction technology has a greater impact on zinc nickel battery, and its profit and lithium battery profit are gradually decreasing. Therefore, with the continuous improvement of carbon emission reduction market, the advantages of zinc nickel battery will become increasingly prominent.
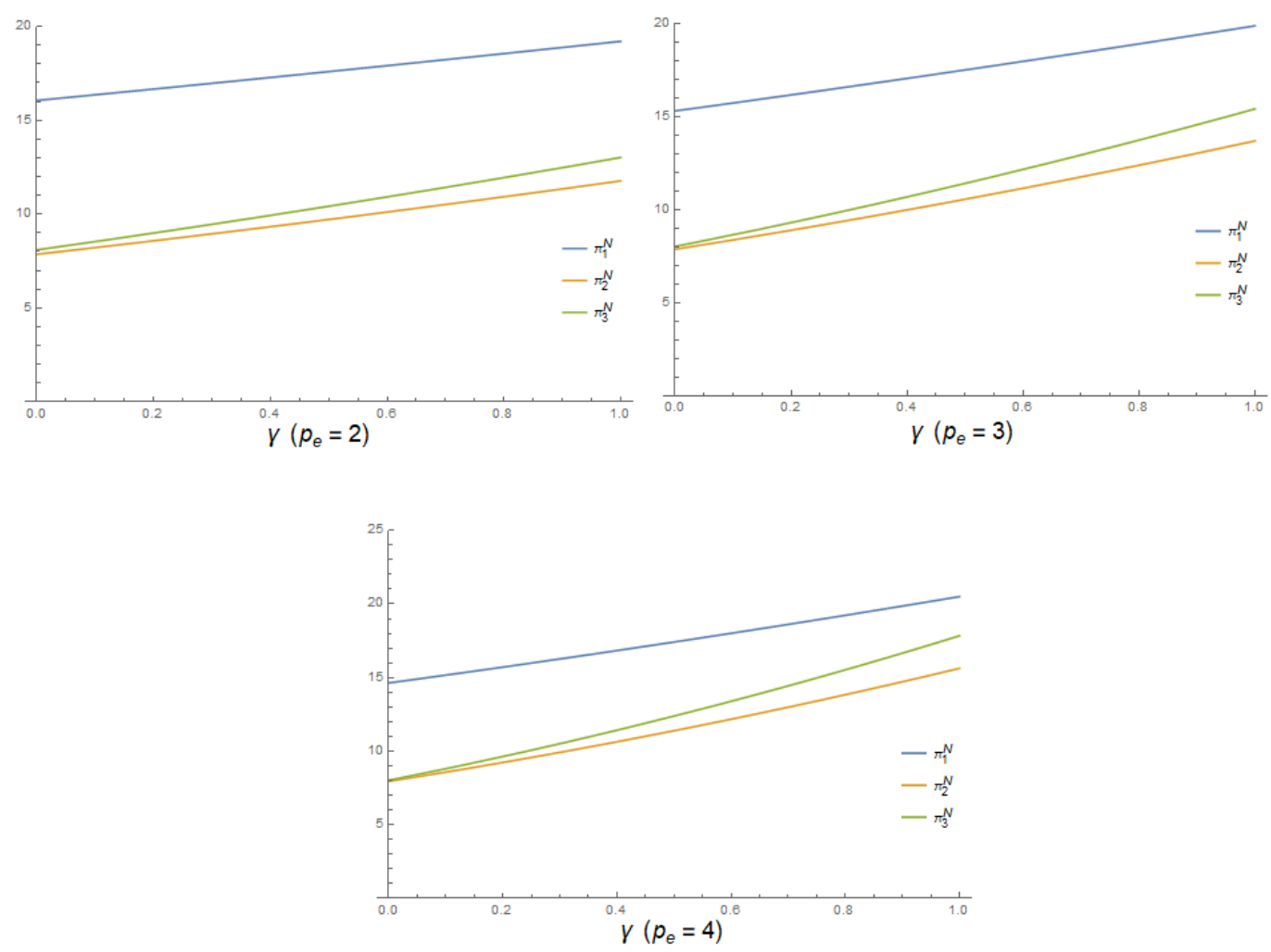

Fig. 3 impact of carbon emission reduction technology renewal coefficient on battery manufacturers' profits under different unit carbon prices

\subsection{Demand disturbance model}

This section will consider demand fluctuations. Demand fluctuation refers to the sudden increase or decrease of product demand caused by sudden time. If demand fluctuates obviously in a short term, serious supply chain bullwhip effect might be triggered under the further promotion of poor information transmission in the supply chain, and in turn there will be loss of customers or unsalable products in the enterprises in the supply chain. Recent years, the $3 \mathrm{C}$ electronic products and new 
energy automobile industry are booming, so that the demand of batteries is increasing, but there are uncertain factors behind the stable increase of the market. For instance, in terms of policy, the extension or cessation of national subsidies for new energy vehicles will promote or inhibit the total market demand for new energy vehicles; in terms of technology, a series of security problems of certain new energy vehicles will lead consumers to take a wait-and-see attitude towards new energy vehicles again, further decreasing the total demand for batteries; In terms of trade, the rise of international trade protectionism and populism has hindered cross-border trade and further caused demand fluctuations. As a consequence, we set total market demand as $a$. However, the overall market demand of the battery industry tends to fluctuate due to the impact of sudden factors such as epidemic situation, trade protectionism or policies. We set demand fluctuation as $\Delta a$. When demand disturbance promotes the development of battery industry, $\Delta a \geqslant 0$; while when demand disturbance is a brake on the development of battery industry $\Delta a \leqslant 0$. Assume that $\Delta a>-a$. When there is emergence in the market, we assume the three manufacturers will unite to form a unified price decision, that is, centralized decision-making, in order to redisit the risk of market. The demand expressions of the three manufacturers are as follows.

$$
\left\{\begin{array}{l}
q_{1}^{D}=(1-(2 \theta+\rho))(a+\Delta a)-\alpha_{1} p_{d}+\alpha_{2} l_{1}^{N}+\beta p_{d} \\
q_{2}^{D}=(\theta+\sigma \rho)(a+\Delta a)-\alpha_{1} p_{d}+\alpha_{2} l_{2}+\beta p_{d} \\
q_{3}^{D}=(\theta+(1-\sigma) \rho)(a+\Delta a)-\alpha_{1} p_{d}+\alpha_{2} l_{3}+\beta p_{d}
\end{array}\right.
$$

$\operatorname{Make}\left(Q^{\vdots}-Q^{*}\right)^{+}=\max \left\{0, Q^{\sim}-Q^{*}\right\},\left(Q^{*}-Q^{\vdots}\right)^{+}=\max \left\{0, Q^{*}-Q^{\ddagger}\right\}$ to represent the adjustment amount of the total production of the supply chain when the total market demand increases and decreases respectively. The actual demand is $Q^{:}=q_{1}^{D}+q_{2}^{D}+q_{3}^{D}$, and the planned demand is the total demand after the balanced price is brought in in the previous section.

So that the profit function after disturbance can be shown as: 
Now the total profits of the three manufactures are:

$$
\begin{aligned}
& \pi_{D}=\left(p_{d}-c_{1}\right) q_{1}^{D}-(1-r) C_{I 1}+\left(E-e_{L}\left(1-\gamma l_{1}^{N}\right) q_{1}^{D}\right) p_{e}+ \\
& (1-\varepsilon \sigma \rho)\left(p_{d}-c_{2}\right) q_{2}^{D}-(1-r) C_{I 2}+\left(E-e_{\mathrm{ZN}}\left(1-\gamma l_{2}\right) q_{2}^{D}\right) p_{e}+ \\
& (1-\varepsilon(1-\sigma) \rho)\left(p_{d}-c_{3}\right) q_{3}^{D}-(1-r) C_{I 3}+\left(E-e_{Z N}\left(1-\gamma l_{3}\right) q_{3}^{D}\right) p_{e}
\end{aligned}
$$

497

498 When the actual demand is over the planned demand, that is $Q^{:} \geq Q^{*}$, the profit 499 function of the supply chain is:

$$
\begin{aligned}
& \pi_{D}=\left(p_{d}-c_{1}\right) q_{1}^{D}-(1-r) C_{I 1}+\left(E-e_{L}\left(1-\gamma l_{1}^{N}\right) q_{1}^{D}\right) p_{e}+ \\
& (1-\varepsilon \sigma \rho)\left(p_{d}-c_{2}\right) q_{2}^{D}-(1-r) C_{I 2}+\left(E-e_{Z N}\left(1-\gamma l_{2}\right) q_{2}^{D}\right) p_{e}+ \\
& (1-\varepsilon(1-\sigma) \rho)\left(p_{d}-c_{3}\right) q_{3}^{D}-(1-r) C_{I 3}+\left(E-e_{Z N}\left(1-\gamma l_{3}\right) q_{3}^{D}\right) p_{e}-u_{1}\left(Q^{:}-Q^{*}\right)
\end{aligned}
$$

$u_{1}$ represents out-of-stock cost of the whole supply chain.

When the planned demand is over the actual demand, that is, $Q^{\text {: }}<Q^{*}$, the profit 504 function of the supply chain is:

$$
\begin{aligned}
& \pi_{D}=\left(p_{d}-c_{1}\right) q_{1}^{D}-(1-r) C_{I 1}+\left(E-e_{L}\left(1-\gamma l_{1}^{N}\right) q_{1}^{D}\right) p_{e}+ \\
& (1-\varepsilon \sigma \rho)\left(p_{d}-c_{2}\right) q_{2}^{D}-(1-r) C_{I 2}+\left(E-e_{Z N}\left(1-\gamma l_{2}\right) q_{2}^{D}\right) p_{e}+ \\
& (1-\varepsilon(1-\sigma) \rho)\left(p_{d}-c_{3}\right) q_{3}^{D}-(1-r) C_{I 3}+\left(E-e_{Z N}\left(1-\gamma l_{3}\right) q_{3}^{D}\right) p_{e}-u_{2}\left(Q^{*}-Q^{\vdots}\right) \\
& u_{2} \text { represents inventory cost of the whole supply chain. }
\end{aligned}
$$

\subsubsection{Equilibrium strategy}

In case of emergency, the three battery manufacturers cooperate to determine the battery price jointly, that is, the decision-making goal is to maximize the total profit of the supply chain. This section will discuss and derive solutions for cases $Q^{:} \geq Q^{*}$ 
512 and $Q^{:}<Q^{*}$ respectively.

513

514 When $Q^{:} \geq Q^{*}$, the optimal decision-making problem of supply chain can be 515 expressed as:

$$
\begin{aligned}
& \operatorname{Max}\left(\pi_{D}\right) \\
& \text { s.t. } Q \geq Q^{*}
\end{aligned}
$$

517 Since $\frac{\partial^{2} \pi_{D}}{\partial\left(p_{d}\right)^{2}}=2\left(\alpha_{1}-\beta\right)(-3+\varepsilon \rho)<0, \pi_{D}$ is a concave function of $p_{d}$, and the 518 constraints are linear inequality constraints. The above optimization problems can be 519 solved according to KKT conditions:

520

521 When $Q^{:}<Q^{*}$, the optimal decision-making problem of supply chain can be expressed as:

$$
\left\{\begin{array}{l}
\frac{\partial \pi_{D}}{\partial p_{d}}+\lambda \frac{\partial\left(Q^{\sim}-Q^{*}\right)}{\partial p_{d}}=0 \\
\lambda\left(Q^{\sim}-Q^{*}\right)=0 \\
\lambda \geq 0
\end{array}\right.
$$

524 The above optimization problems can be solved according to KKT conditions:

$$
\begin{aligned}
& \operatorname{Max}\left(\pi_{D}\right) \\
& \text { s.t. } Q: Q^{*}
\end{aligned}
$$

$$
\left\{\begin{array}{l}
\frac{\partial \pi_{D}}{\partial p_{d}}+\lambda \frac{\partial\left(Q^{*}-Q^{\sim}\right)}{\partial p_{d}}=0 \\
\lambda\left(Q^{*}-Q^{\sim}\right)=0 \\
\lambda \geq 0
\end{array}\right.
$$

526

527 Lemma 4:

528 When $\Delta a<\Delta a_{2}, p_{d}=p_{d(\lambda=0)}^{2}$;

529 When $\Delta a_{2}<\Delta a<\Delta a_{1}, p_{d}=p_{d(\lambda>0)}^{1}=p_{d(\lambda>0)}^{2}$;

530 When $\Delta a_{1}<\Delta a, p_{d}=p_{d(\lambda=0)}^{1}$;

531 Among them: 


$$
p_{d(\lambda=0)}^{2}=p_{d(\lambda=0)}^{1}-\frac{3\left(u_{1}+u_{2}\right)}{6-2 \varepsilon \rho}
$$

533

$$
p_{d(\lambda=0)}^{1}=\frac{1}{2\left(\alpha_{1}-\beta\right)(-3+\varepsilon \rho)}\left(\begin{array}{l}
-l_{1}^{N} \alpha_{2}-3 u_{1}\left(\alpha_{1}-\beta\right)+c_{1}\left(-\alpha_{1}+\beta\right)+e_{l} p e\left(\alpha_{1}-\beta\right) \\
\left(-1+l_{1}^{N} \gamma\right)+e_{z} p_{e}\left(\alpha_{1}-\beta\right)\left(-1+l_{2} \gamma\right) \\
+e_{z} p_{e}\left(\alpha_{1}-\beta\right)\left(-1+l_{3} \gamma\right)+(a+\Delta a)(-1+2 \theta+\rho)- \\
l_{3} \alpha_{2} A+c_{3}\left(-\alpha_{1}+\beta\right) A-(a+\Delta a) A(\theta+\rho-\rho \sigma) \\
+l_{2} \alpha_{2} B+c_{2}\left(\alpha_{1}-\beta\right) B+(a+\Delta a)(\theta+\rho \sigma) B
\end{array}\right)
$$

534

$$
\begin{aligned}
& \left(3\left(l_{1}^{N}+l_{2}+l_{2}\right) \alpha_{1} \alpha_{2}-3 T\left(\alpha_{1}+\beta\right)-3 \alpha_{1}\left(\alpha_{1}-\beta\right)\right. \\
& \left(c_{1}+c_{2}+c_{3}+3 u_{1}+p_{e}\left(e_{l}+2 e_{z}-\left(e_{l} l_{1}^{N}+e_{z}\left(l_{2}+l_{3}\right)\right) \gamma\right)\right)+ \\
& \varepsilon \rho\left(T\left(\alpha_{1}+\beta\right)-\alpha 1\left(\begin{array}{l}
2\left(l_{1}^{N}+l_{2}\right) \alpha_{2}-l_{3} \alpha_{2}+3 c_{3}\left(\alpha_{1}-\beta\right)(-1+\sigma) \\
+3\left(\left(-l_{2}+l_{3}\right) \alpha_{2}+c_{2}\left(-\alpha_{1}+\beta\right)\right) \sigma
\end{array}\right)\right)+ \\
& \Delta a_{1}=\frac{\left(a \alpha_{1}(3+\varepsilon \rho(-2+3 \theta+3 \rho+6 \rho(-1+\sigma) \sigma))\right.}{-\left(\alpha_{1}(3+\varepsilon \rho(-2+3 \theta+3 \rho+6 \rho(-1+\sigma) \sigma))\right)}
\end{aligned}
$$

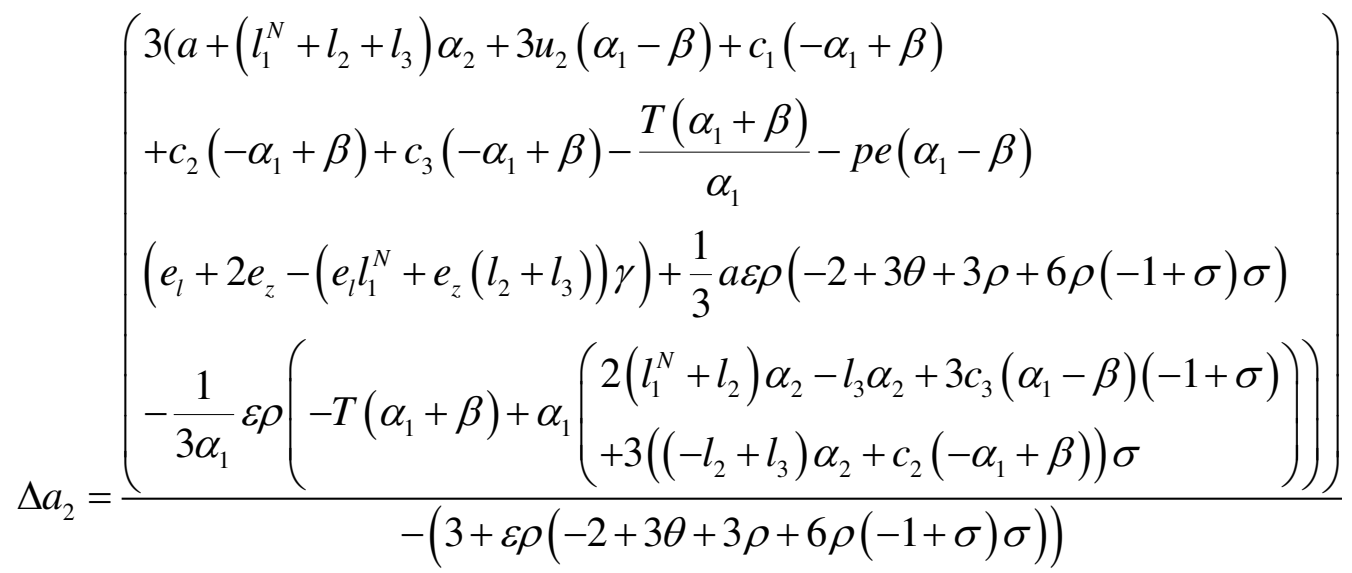

535

Prove:

For lemma 4, firstly, according to the calculation results in the previous section and the assumptions in this section, we can get:

$$
Q^{:}-Q^{*}=a+\Delta a-3 p_{d} \alpha_{1}+l_{1}^{N} \alpha_{2}+l_{2} \alpha_{2}+l_{3} \alpha_{2}+3 p_{d} \beta-\frac{1}{2 \alpha_{1}}\left(\alpha_{1}+\beta\right) T
$$

Among them:

$$
T=a+\left(l_{1}^{N}+l_{2}+l_{3}\right) \alpha_{2}+\left(\alpha_{1}-\beta\right)\left(-c 1-c 2-c 3+p_{e}\left(e_{l}\left(-1+l_{1}^{N} \gamma\right)+\frac{e_{z}\left(-1+l_{3} \gamma\right)}{1+\varepsilon \rho(-1+\sigma)}+\frac{e_{z}-e_{z} l_{2} \gamma}{-1+\varepsilon \rho \sigma}\right)\right)
$$


When $\lambda=0$, the total profit of the supply chain obtains the first-order derivative of the price, and the derivative function is 0 to obtain the optimal price at this time:

545

546

547

548

549

550 Bring the optimal price $p_{d}$ in $\frac{\partial \pi_{D}}{\partial p_{d}}+\lambda \frac{\partial\left(Q^{\sim}-Q^{*}\right)}{\partial p_{d}}=0$, and get the value of $\lambda$ :

When $\lambda>0$, let $Q^{\sim}-Q^{*}=0$, and get the optimal price:

$$
p_{d(\lambda>0)}^{1}=\frac{1}{3 \alpha_{1}-3 \beta}\left(a+\Delta a+l_{1}^{N} \alpha_{2}+l_{2} \alpha_{2}+l_{3} \alpha_{2}-\frac{1}{2 \alpha_{1}}\left(\alpha_{1}+\beta\right) T\right)
$$

$$
p_{d(\lambda=0)}^{1}=\frac{1}{2\left(\alpha_{1}-\beta\right)(-3+\varepsilon \rho)}\left(\begin{array}{l}
-l_{1}^{N} \alpha_{2}-3 u_{1}\left(\alpha_{1}-\beta\right)+c_{1}\left(-\alpha_{1}+\beta\right)+e_{l} p e\left(\alpha_{1}-\beta\right) \\
\left(-1+l_{1}^{N} \gamma\right)+e_{z} p_{e}\left(\alpha_{1}-\beta\right)\left(-1+l_{2} \gamma\right) \\
+e_{z} p_{e}\left(\alpha_{1}-\beta\right)\left(-1+l_{3} \gamma\right)+(a+\Delta a)(-1+2 \theta+\rho)- \\
l_{3} \alpha_{2} A+c_{3}\left(-\alpha_{1}+\beta\right) A-(a+\Delta a) A(\theta+\rho-\rho \sigma) \\
+l_{2} \alpha_{2} B+c_{2}\left(\alpha_{1}-\beta\right) B+(a+\Delta a)(\theta+\rho \sigma) B
\end{array}\right)
$$

$$
\frac{1}{3\left(-3 \alpha_{1}+3 \beta\right)}\left(\begin{array}{l}
3\left(l_{1}^{N}+l_{2}+l_{3}\right) \alpha_{2}-\frac{3 T\left(\alpha_{1}+\beta\right)}{\alpha_{1}}-3\left(\alpha_{1}-\beta\right)\left(c_{1}+c_{2}+c_{3}+3 u_{1}\right. \\
+p_{e}\left(e_{l}+2 e z-\left(e_{l} l_{1}^{N}+e z\left(l_{2}+l_{3}\right)\right) \gamma\right) \\
-\frac{1}{\alpha_{1}} \varepsilon \rho\left(-T\left(\alpha_{1}+\beta\right)+\alpha_{1}\left(2\left(l_{1}^{N}+l_{2}\right) \alpha_{2}-\right.\right. \\
\left.\left.l_{3} \alpha_{2}+3 c_{3}\left(\alpha_{1}-\beta\right)(-1+\sigma)+3\left(-c_{2} \alpha_{1}-l_{2} \alpha_{2}+l_{3} \alpha_{2}+c_{2} \beta\right) \sigma\right)\right) \\
+a(3+\varepsilon \rho(-2+3 \theta+3 \rho+6 \rho(-1+\sigma) \sigma)) \\
+\Delta a(3+\varepsilon \rho(-2+3 \theta+3 \rho+6 \rho(-1+\sigma) \sigma))
\end{array}\right)
$$

552

Due to $\lambda>0$, the $\Delta a$ satisfies:

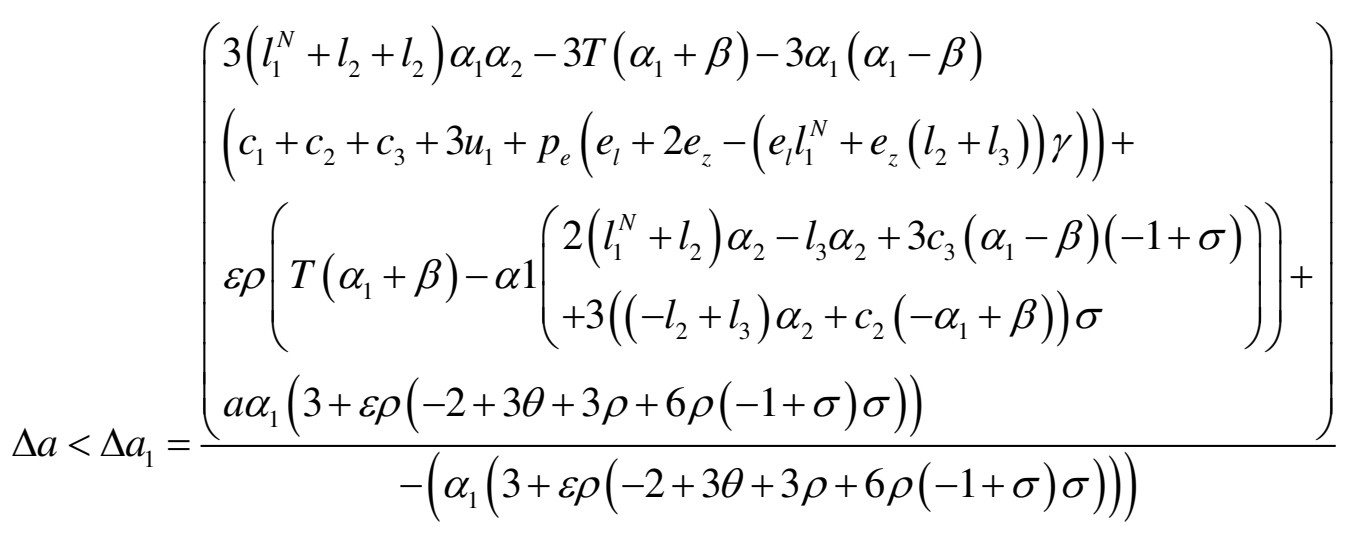


Similarly, we can get $p_{d(\lambda=0)}^{2}, p_{d(\lambda>0)}^{2}$ and $\Delta a_{2}$.

According to lemma 4, when the demand disturbance is in different ranges, the optimal price of supply chain decision-making is not the same, which is divided into three different regions according to the size of supply chain. At that time, the original production plan of the supply chain could not meet the increased market demand after the disturbance, and the battery manufacturer needed to temporarily increase the output to improve the profits of the supply chain; At that time, the original production plan of the supply chain greatly exceeded the reduced market demand after the disturbance, and battery manufacturers needed to temporarily reduce production to improve the profits of the supply chain. Finally, when the disturbance is satisfied, the manufacturer only needs to complete the production according to the original plan, which can avoid unnecessary replenishment costs and processing costs. The manufacturer only needs to adjust the sales price to maximize the profit of the supply chain.

\subsubsection{Numerical simulation}

According to the calculation results in the previous section, this section will bring specific values to conduct numerical simulation analysis on Supply Chain Pricing and profit under demand disturbance. In order to be consistent with the previous analysis, the assignment of this section is the same as the previous one, that is:

$$
a=10, \theta=0.2, \sigma=0.3, \alpha_{1}=0.5, \alpha_{2}=0.5, \beta=0.3, c_{1}=0.1, c_{2}=0.1, c_{3}=0.1,
$$$$
C_{1}=1, C_{2}=2, C_{3}=3, r=0.1, e_{l}=1.2, e_{z}=1.1, p_{e}=2, e=1, \rho=0.1, \varepsilon=0.1 \text {, }
$$

$$
\tau=0.3, l_{L}=1, l_{\text {ZN }}=1.2, \gamma=0.2, u_{1}=1, u_{2}=1
$$

Different from the previous section, this section assigns the out-of-stock cost and inventory cost of the supply chain. In the following, we will focus on the analysis of supply chain pricing, that is, the impact of profit under the changes of total market demand, inventory cost and out-of-stock cost. 
According to lemma 4, the change of inventory cost and out-of-stock cost will affect the price decision in supply chain. The impact of the change of inventory cost and out-of-stock cost on the change threshold of total market demand, $\Delta a_{1}$ and $\Delta a_{2}$ is shown in figure 4 . The Out-of-stock cost, ${ }^{u_{1}}$, has an influence on $\Delta a_{1}$, and the inventory cost, $u_{2}$, has an influence on $\Delta a_{2}$.It can be seen that $\Delta a_{1}$ increases generally with the rise of ${ }^{u_{1}}$, while $\Delta a_{2}$ decreases generally with the rise of $u_{2}$. Thus, the rise of inventory cost and out-of-stock cost will expand the $\Delta a_{2}<\Delta a<\Delta a_{1}$ area among the three. In this area, the supply chain will make the planned demand be equal to demand after disturbance by changing the price. So, the high inventory cost and out-of-stock cost will make the supply chain increasingly ignore the changes of market demand, and in turn produce according to original plans.

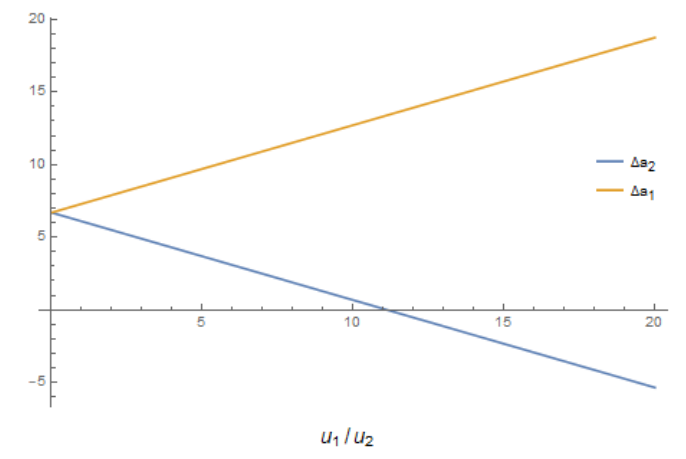

Fig.4 impact of changes in inventory cost and out-of-stock cost on $\Delta a_{1}, \Delta a_{2}$

Figure 5 displays the influence the total change in market demand on supply chain prices. According to lemma 4, the influence of the total change of market demand on price is a piecewise function, so that the figure shows the three periods of influence of demand disturbance. With the rise of demand disturbance, the optimal price of the supply chain is constantly rising. In the stage when the actual demand is greater than the planned demand and the opposite, the growth of demand disturbance has the same effect on the change of price change, while when the actual demand is equal to the planned demand, the influence of demand disturbance on price change is obviously 
higher than the other two stages. In short, when the demand disturbance is in a moderate region, the optimal price sensitivity of the supply chain is higher.

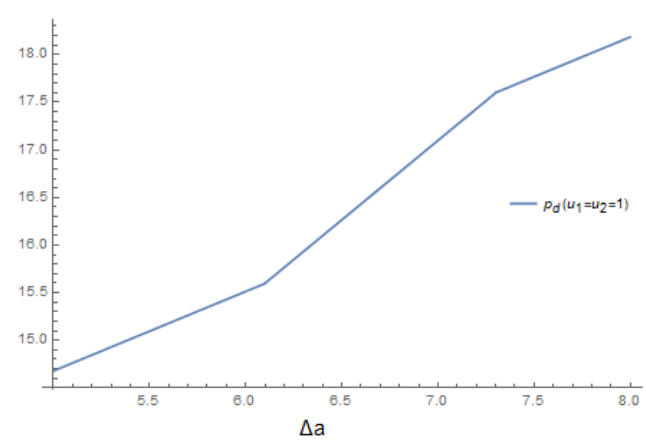

606

607

608

609

610

611

612

613

614

615

616

617

618

619

620

Fig. 5 the influence of $\Delta a$ on the optimal price of supply chain

Figure 6 describes the change of optimal price of supply chain under different out-of-stock costs and inventory costs. When the inventory rises, the optimal price decreases in the region of $\Delta a<\Delta a_{2}$, while when the out-of-stock costs rise, the optimal price decreases in the region of $\Delta a_{1}<\Delta a$. As a result, out-of-stock cost and inventory cost have different effects on the optimal price of supply chain. The increase of inventory cost will reduce the optimal price; The increase of out-of-stock cost will increase the optimal price.

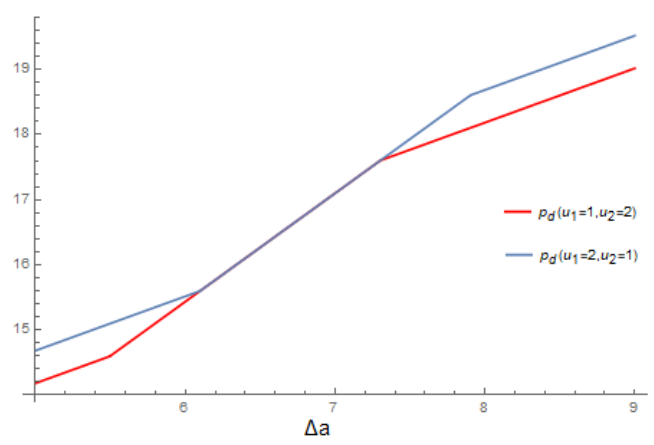

Fig.6 Effects of $\Delta a$ on the optimal price of supply chain under different out-of-stock costs and inventory costs

Figure 7 depicts the change of supply chain profit caused by demand disturbance. The 
variation diagram of total profit of supply chain disturbed by demand is still composed of a piecewise function. It can be seen from the figure that with the increase of demand disturbance value, the profit of supply chain is increasing.

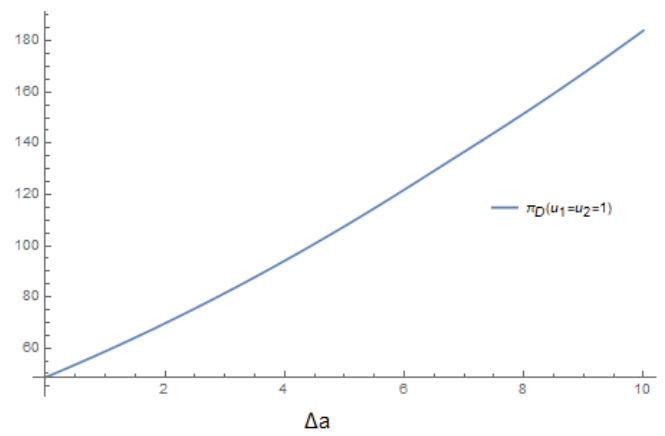

Fig.7 Effect of $\Delta a$ on profit of supply chain

Figure 8 then compares the supply chain profits under different shortage costs and inventory costs. Figure 8 (a) shows that the profit of the supply chain decreases when the inventory cost increases and the out-of-stock cost remains unchanged, and figure 8 (b) shows that the profit of the supply chain also decreases when the out-of-stock cost increases and the inventory cost remains unchanged. The difference is that different costs affect the supply chain profit in different regions. Inventory cost affects the supply chain profit in the region with small demand disturbance, while shortage cost affects the supply chain profit in the region with large demand disturbance.

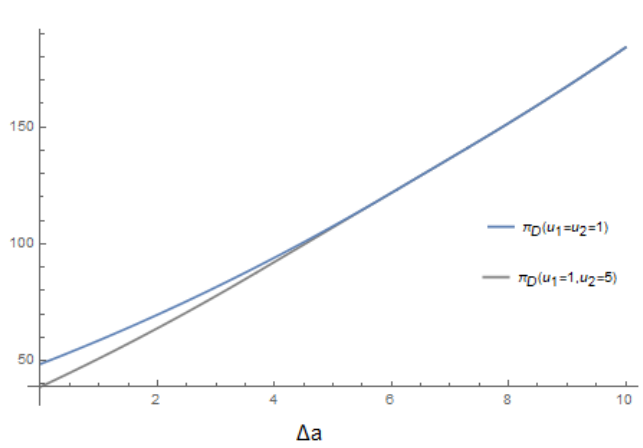

(a)

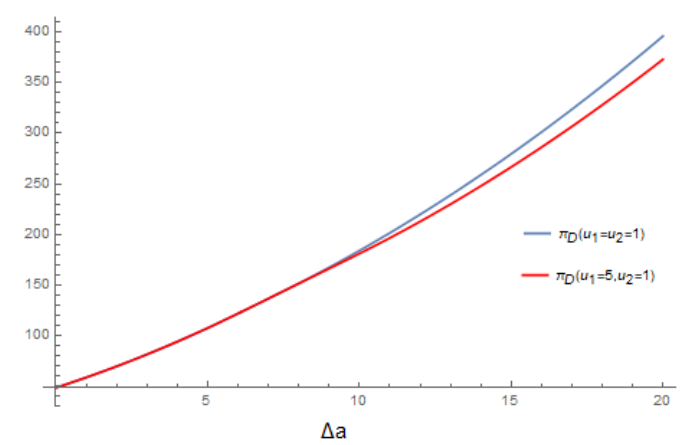

(b)

Fig. 8 Impact of $\Delta a$ on supply chain profit under different out-of-stock costs and inventory costs 


\subsection{Evolutionary game model}

641 In the game of the basic model, it is assumed that the members of the supply chain are completely rational, and they would not be disturbed be exterior environment. Now,

643 all the members of the supply chain reach the optimal solution directly, but One cycle 644 game does not have long-term effectiveness. In evolutionary game, the members of 645 supply chain who join in the game are affected by incomplete information and 646 uncertain environment, so they can only make limited-rational decisions. That is, the 647 players are not completely forward-looking, making the system reach equilibrium gradually rather than once. Each participant will gradually adjust their decision 649 variables to the equilibrium point according to a certain adjustment speed.

650

In the evolutionary game model, the battery manufacturer adjusts to the optimal price according to the sales price of the previous period, which forms a complex system. Meanwhile, it can be seen that the decision-making process is a Markov process, 654 including three decision variables: $p_{1(t)}^{N}, p_{2(t)}^{N}, p_{3(t)}^{N}$, and in turn the discrete system 655 dynamic model can be constructed according to the process of state transition:

$$
\left\{\begin{array}{l}
p_{1(t+1)}^{N}=p_{1(t)}^{N}+v_{1} p_{1(t)}^{N} \frac{\partial \pi_{1}^{N}}{\partial p_{1}^{N}} \\
p_{2(t+1)}^{N}=p_{2(t)}^{N}+v_{2} p_{2(t)}^{N} \frac{\partial \pi_{2}^{N}}{\partial p_{2}^{N}} \\
p_{3(t+1)}^{N}=p_{3(t)}^{N}+v_{3} p_{3(t)}^{N} \frac{\partial \pi_{3}^{N}}{\partial p_{3}^{N}}
\end{array}\right.
$$

$657 v_{1}$ represents the price adjustment speed of lithium battery manufacturers; $v_{2}$ the 658 price adjustment speed of No.1 zinc-nickel battery manufacturers; $v_{3}$ represents the 659 price adjustment speed of No.2 zinc-nickel battery manufacturers.

$$
\begin{aligned}
& \frac{\partial \pi_{1}^{N}}{\partial p_{1}^{N}}=-p_{1}^{N} \alpha_{1}+l_{1}^{N} \alpha_{2}+\left(-c_{1}+p_{1}^{N}\right)\left(-\alpha_{1}-\beta\right)-\left(p_{1}^{N}-p_{2}^{N}-p_{3}^{N}\right) \beta-e_{L} p_{e}\left(-\alpha_{1}-\beta\right)\left(1-l_{1}^{N} \gamma\right) \\
& +a(1-2 \theta-\rho)
\end{aligned}
$$




$$
\begin{aligned}
& \frac{\partial \pi_{2}^{N}}{\partial p_{2}^{N}}=-e_{z} p_{e}\left(-\alpha_{1}-\beta\right)\left(1-l_{2} \gamma\right)+\left(-c_{2}+p_{2}^{N}\right)\left(-\alpha_{1}-\beta\right)(1-\varepsilon \rho \sigma) \\
& +(1-\varepsilon \rho \sigma)\left(-p_{2}^{N} \alpha_{1}+l_{2} \alpha_{2}-\left(-p_{1}^{N}+p_{2}^{N}-p_{3}^{N}\right) \beta+a(\theta+\rho \sigma)\right)
\end{aligned}
$$

$$
\frac{\partial \pi_{3}^{N}}{\partial p_{3}^{N}}=-e_{z} p_{e}\left(-\alpha_{1}-\beta\right)\left(1-l_{3} \gamma\right)+\left(-c_{3}+p_{3}^{N}\right)\left(-\alpha_{1}-\beta\right)(1-\varepsilon \rho(1-\sigma))
$$

$+\left(-p_{3}^{N} \alpha_{1}+l_{3} \alpha_{2}-\left(-p_{1}^{N}-p_{2}^{N}+p_{3}^{N}\right) \beta+a(\theta+\rho(1-\sigma))\right)(1-\varepsilon \rho(1-\sigma))$

666

Next, the system stability of the model will be analyzed. Firstly, the Jacobian matrix of the dynamic system is solved as follows:

$$
J_{A}=\left(\begin{array}{ccc}
j_{11} & \beta p_{1(t)}^{N} v_{1} & \beta p_{1(t)}^{N} v_{1} \\
\beta p_{2(t)}^{N} v_{2}(1-\rho \sigma \epsilon) & j_{22} & \beta p_{2(t)}^{N} v_{2}(1-\rho \sigma \epsilon) \\
\beta p_{3(t)}^{N} v_{3}(1-\rho(1-\sigma) \epsilon) & \beta p_{3(t)}^{N} v_{3}(1-\rho(1-\sigma) \epsilon) & j_{33}
\end{array}\right)
$$

$j_{11}=v_{1}\left(\begin{array}{l}a(-2 \theta-\rho+1)+\left(-\alpha_{1}-\beta\right)\left(p_{1(t)}^{N}-c_{1}\right)-e_{l} p_{e}\left(-\alpha_{1}-\beta\right) \\ \left(1-\gamma l_{1}^{N}\right)+\alpha_{2} l_{1}^{N}+\alpha_{1}\left(-p_{1(t)}^{N}\right)-\beta\left(p_{1(t)}^{N}-p_{2(t)}^{N}-p_{3(t)}^{N}\right)\end{array}\right)+p_{1(t)}^{N} v_{1}\left(-2 \alpha_{1}-2 \beta\right)+1$

$j_{22}=v_{2}\left(\begin{array}{l}(1-\rho \sigma \epsilon)\left(a(\theta+\rho \sigma)+\alpha_{2} l_{2}-\beta\left(-p_{1(t)}^{N}+p_{2(t)}^{N}-p_{3(t)}^{N}\right)+\alpha_{1}\left(-p_{2(t)}^{N}\right)\right) \\ +\left(-\alpha_{1}-\beta\right)\left(p_{2(t)}^{N}-c 2\right)(1-\rho \sigma \epsilon)-e_{z} p_{e}\left(-\alpha_{1}-\beta\right)\left(1-\gamma l_{2}\right)\end{array}\right)+2 p_{2(t)}^{N} v_{2}\left(-\alpha_{1}-\beta\right)(1-\rho \sigma \epsilon)+1$

$j_{33}=v_{3}\left(\begin{array}{l}(1-\rho(1-\sigma) \epsilon)\left(a(\theta+\rho(1-\sigma))+\alpha_{2} l_{3}-\beta\left(-p_{1(t)}^{N}-p_{2(t)}^{N}+p_{3(t)}^{N}\right)+\alpha_{1}\left(-p_{3(t)}^{N}\right)\right) \\ +\left(-\alpha_{1}-\beta\right)\left(p_{3(t)}^{N}-c_{3}\right)(1-\rho(1-\sigma) \epsilon)-e_{2} p_{e}\left(-\alpha_{1}-\beta\right)\left(1-\gamma l_{3}\right)\end{array}\right)+2 p_{3(t)}^{N} v_{3}\left(-\alpha_{1}-\beta\right)(1-\rho(1-\sigma) \epsilon)+1$

The specific stable point of the system is solved by bringing in relevant numerical values:

$$
a=10, \theta=0.2, \sigma=0.3, \alpha_{1}=0.5, \alpha_{2}=0.5, \beta=0.3, c_{1}=0.1, c_{2}=0.1, c_{3}=0.1,
$$$$
C_{1}=1, C_{2}=2, C_{3}=3, r=0.1, e_{l}=1.2, e_{z}=1.1, p_{e}=2, e=1, \rho=0.1, \varepsilon=0.1 \text {, }
$$

$$
\tau=0.3, l_{L}=1, l_{\text {ZN }}=1.2, \gamma=0.2
$$

\section{Bring the parameters in the Jacobian matrix and get the coefficients of characteristic} polynomials as follows:

$$
\begin{aligned}
& A_{0}=-1+10.130 v_{1}+7.774 v_{2}-75.982 v_{1} v_{2}+8.092 v_{3}-79.090 v_{1} v_{3}-60.694 v_{2} v_{3}+561.633 v_{1} v_{2} v_{3} \\
& A_{1}=3-20.260 v_{1}-15.548 v_{2}+75.982 v_{1} v_{2}-16.184 v_{3}+79.090 v_{1} v_{3}+60.6951 v_{2} v_{3} \\
& A_{2}=-3+10.130 v_{1}+7.774 v_{2}+8.092 v_{3} \\
& A_{3}=1
\end{aligned}
$$


According to Jury criterion, when the characteristic polynomial above satisfies the constraint conditions below, the system enters a stable state.

$$
\begin{aligned}
& A_{0}+A_{1}+A_{2}+A_{3}>0 \\
& A_{0}-A_{1}+A_{2}-A_{3}<0 \\
& \left|A_{0}\right|<A_{3} \\
& \left|A_{0}^{2}-A_{3}^{2}\right|>\left|A_{0} A_{2}-A_{1} A_{3}\right|
\end{aligned}
$$

In this paper, the stability region of the system under the change of adjustment speed is drawn by using Mathematica software according to the restrain conditions above. As shown in Figure 2, the three coordinates respectively represent the adjustment speed of the sales price level of the three battery manufacturers, and the region surrounded by the yellow curved surface is the stability region of the system. when the adjustment speed is in that region, there is a stable solution to the manufacturers' multi cycle game. However, when the adjustment speed is beyond the stability region, the system would lose stability and enter a period of doubling bifurcation state or chaotic state. Such phenomenon shows that in order to make the market enter an orderly and balanced state, battery manufacturers should control the adjustment speed of decision variables within a certain range.

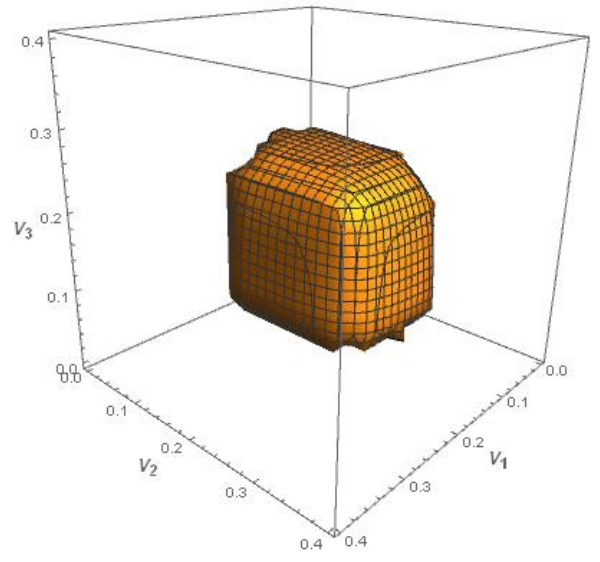

Fig.9 Stability range of system adjustment speed

The 3D figure 9 directly shows the adjustment speed stability region of the long-term game of the three battery manufacturers. In order to analyze the specific effect of adjustment speed on long-term game in detail, this paper makes a detailed analysis in the form of bifurcation diagram by using MATLAB software. The specific methods are as follows: The system is iterated continuously under different adjustment speed 
699 values, and then the strategy changes after a certain number of iterations are drawn 700 into a scatter diagram.

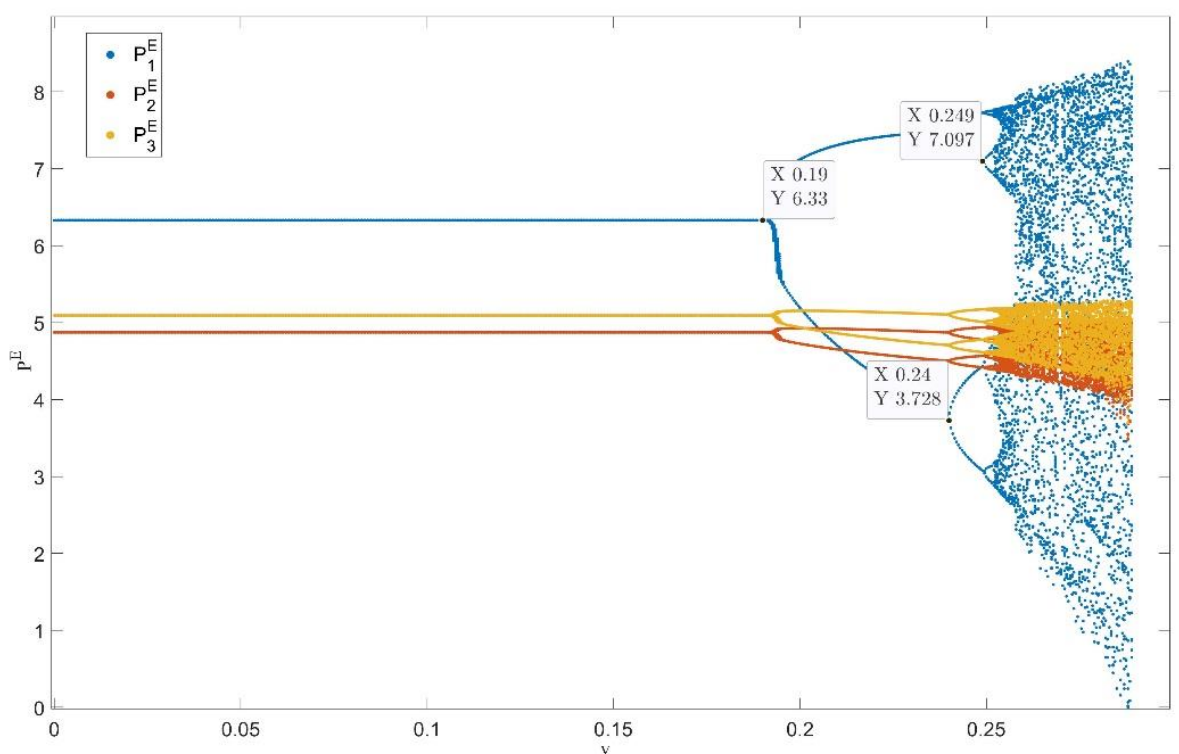

701

702 Fig.10Bifurcation diagram of price adjustment speed of lithium battery manufacturers 703

704 Figure 10 shows the Influence of sales price adjustment speed of lithium battery 705 manufacturers, $v_{1}$, on manufacturers' sales price decision, and $v_{2}=0.1, v_{3}=0.1$. 706 When $v_{1}=0.19$, the sale prices of the two manufacturers are remain unchanged; 707 When $0.19<v_{1}<0.24$, the system enters the double period bifurcation state; When $7080.24<v_{1}<0.249$, the system enters the quadruple period bifurcation state; when $709 \quad 0.249<v_{1}$, the system falls into chaos. 


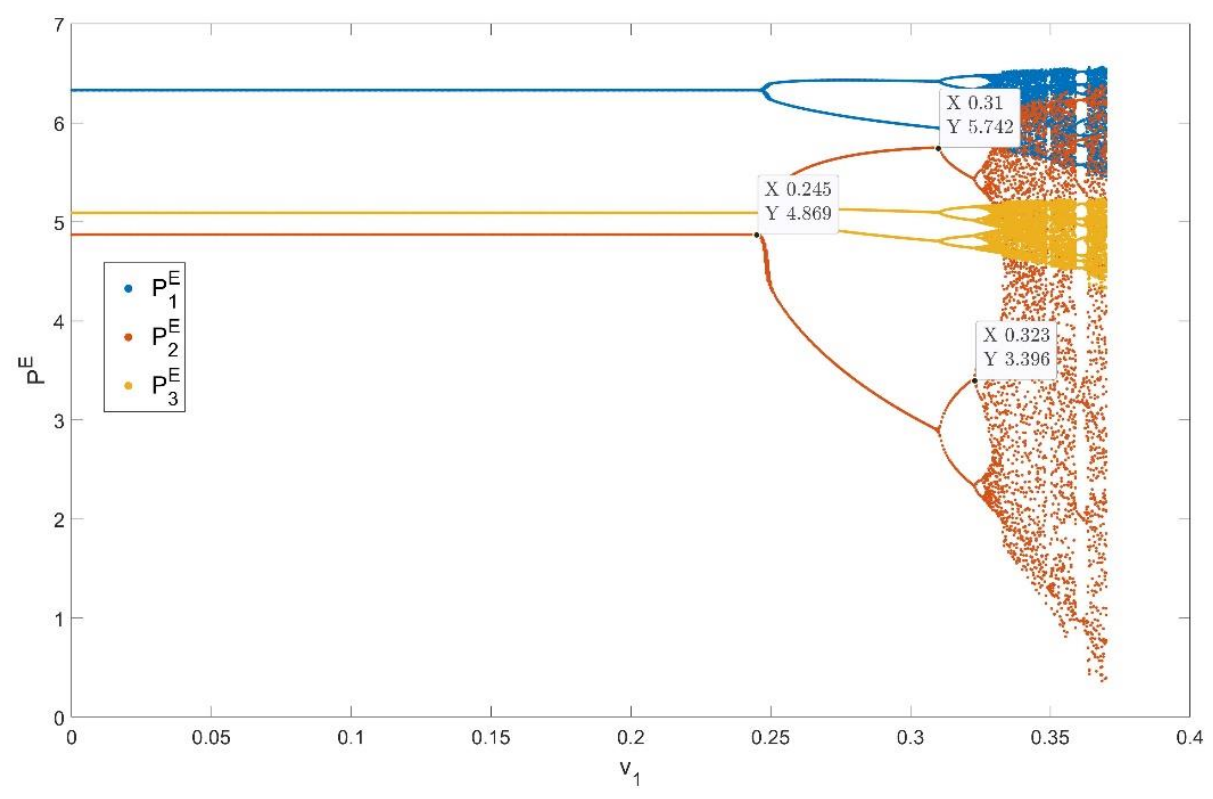

710

711

712

713 714 battery manufacturers, $v_{2}$, on manufacturers' sales price decision, and $v_{1}=0.1$, $715 v_{3}=0.1$. When $v_{2}<0.215$, the sale prices of the two manufacturers are remain 716 unchanged; When $0.215<v_{2}<0.31$, the system enters the double period bifurcation 717 state; When $0.31<v_{2}<0.323$, the system enters the quadruple period bifurcation 718 state; when $v_{2}>0.323$, the system falls into chaos.

Fig. 11 bifurcation diagram of price adjustment speed of No. 1 zinc-nickel battery manufacturer

Figure 11 shows the influence of sales price adjustment speed of No.1 zinc-nickel

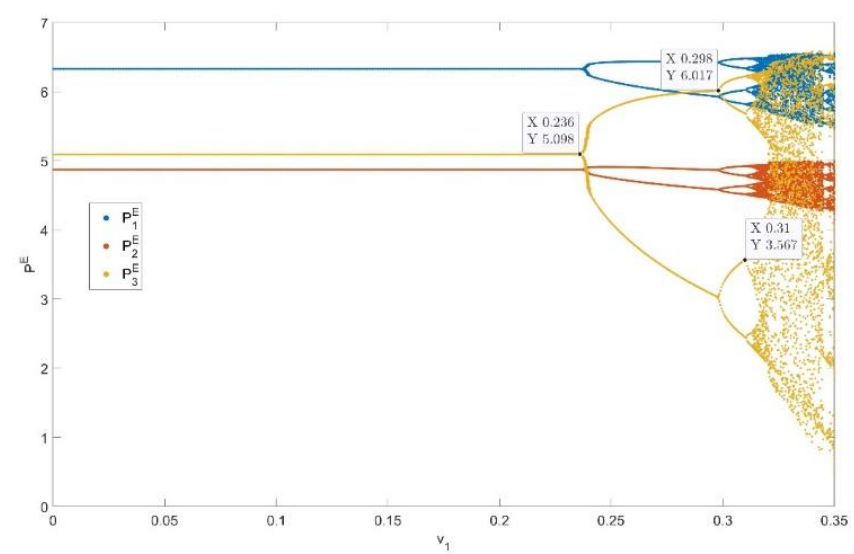

Fig.12 Bifurcation diagram of price adjustment speed of No. 2 zinc nickel battery manufacturer 
723 battery manufacturers, $v_{3}$, on manufacturers' sales price decision, and $v_{1}=0.1$, 724

Figure 12 shows the influence of sales price adjustment speed of No.2 zinc-nickel $v_{2}=0.1$. When $v_{2}<0.236$, the sale prices of the two manufacturers are remain unchanged; When $0.236<v_{2}<0.298$, the system enters the double period bifurcation state; When $0.298<v_{2}<0.31$, the system enters the quadruple period bifurcation state; when $v_{2}>0.323$, the system falls into chaos.

In conclusion, if the price adjustment speeds of the batteries manufacturers are out of a certain range in the evolutionary game, the competition and game in market will be out of order, damaging the profits of every member of the supply chain. Therefore, there should be corresponding adjustment speed controlled to maintain the stability of the system and the order of the market competition.

\section{Results and Discussion}

This paper studies the competition and cooperation of battery supply chain including two zinc-nickel battery manufacturers and a lithium battery manufacturer. This paper sets up two models: a basic model and a demand disturbance model. In the basic model, two zinc-nickel battery manufacturers and a lithium battery manufacturer adopt the price competition strategy at the same time, and the zinc-nickel battery manufacturers expand their market effect by cooperating with China Mobile and other communication companies. In demand disturbance model, due to the social emergencies, the three battery manufacturers cope with the demand disturbance in market by cooperating.

Through the analysis of the above two models, the main conclusions are as follows:

In the basic model, when the consumers are sensitive with technology level, the prices set by manufacturers rise with the improvement of technology level; The greater the consumer preference for zinc-nickel battery, the higher the price of zinc-nickel battery; With the rise of the updating parameter of carbon emission technology, the optimal 
776• We thank the reviewers and associate editor for their careful reading and helpful 777 comments on the revision of paper. The researchwas supported by the Innovation

prices of the three manufacturers will decrease; When the market promotion rate is in the moderate range, the price of zinc-nickel batteries will be higher than that of the lithium batteries.

In demand disturbance model, the supply chain makes different decisions of optimal prices according to different range of demand disturbance. In numerical simulation, with the rise of shortage costs and inventory costs, the region in which the planned demand is equal to the demand after disturbance will expand, and the increase of inventory costs will reduce the optimal price, while the increase of shortage cost will increase the optimal price.

In evolutionary game model, the price adjustment speed of battery manufacturers should be controlled within a certain range, remaining the stability of the system and the order of the market competition.

It can be seen from the conclusions that if we want to realize the positive incentive of the technology to price of products, we need to improve consumers' sensitivity to technology level, that is, we need to enhance the propaganda of technology. In terms of energy-saving and emission-reduction, the battery manufacturers should improve the level of carbon emission technology, so that their products can gain more advantages in the competition with products at the same level. In terms of zinc-nickel battery manufacturers, they are supposed to choose appropriate market promoting rate, while higher or loew rate may lead to damage to profits. Facing with emergencies, the supply chain can formulate the optimal price according to demand disturbance.

\section{Acknowledgement :} Fund of Tianjin University. 
Author contribution

Bing Zhang, Meihong Zhu,Lixiao : Thesis architecture design, writing the original draft.

Junhai Ma: Supervision and project administration.

Bing Zhang,Tiantong Xu reviewing, preparing final draft, and formatting.

Junhai Ma Li Zhao: Investigation, validation, Programming and calculation and editing.

Bing Zhang,Tiantong Xu: Methodology And experimental calculations.

Data Availability Supplementary data to this articlewill be provided upon request.

\section{Declarations}

Ethics approval Not applicable

Consent to participate Not applicable

Consent for publication Not applicable

Conflicts of Interest: The authors declare no conflict of interest regarding the publication of this paper.

\section{References}

Bao, B., Ma, J., \& Goh, M. (2020). Short-and long-term repeated game behaviours of two parallel supply chains based on government subsidy in the vehicle market. International Journal of Production Research, 58(24), 7507-7530.

Chen, L., Yang, Z., Wang, L., \& Qin, H. (2019). Rational synthesis of 3D ZnO-Cu-C yolk-shell hybrid microspheres and their high performance as anode material for zinc-nickel secondary batteries. Ceramics International, 45(8), 10792-10799. Ceramics International, 2019, 45(8): 1079 2-10799.

Chen, W., \& Hu, Z. H. (2018). Using evolutionary game theory to study governments and manufacturers' behavioral strategies under various carbon taxes and subsidies. Journal of cleaner production, 201, 123-141.

Chopra, S., \& Sodhi, M. S. (2004). Supply-chain breakdown. MIT Sloan management review, 46(1), 53-61.

Chutani, A., \& Sethi, S. P. (2018). Dynamic cooperative advertising under manufacturer and retailer level competition. European Journal of Operational Research, 268(2), 635-652.

Clausen, J., Larsen, A., \& Larsen, J. (2010). Disruption Management-Foreword. Computers \& Operations Research, 37(5), 807-808.

Cui, C., Li, M., \& Zhang, X. (2018). In-situ cutting of graphene into short nanoribbons with applications to Ni-Zn batteries. Scientific reports, 8(1), 1-9. 
Cui, C., Li, M., Zhou, X., \& Zhang, X. (2019). Synthesis of ZnO/carbon nanotube composites for enhanced electrochemical performance of $\mathrm{Ni}-\mathrm{Zn}$ secondary batteries. Materials Research Bulletin, 112, 261-268.

Gao, Q., \& Ma, J. (2009). Chaos and Hopf bifurcation of a finance system. Nonlinear Dynamics, 58(1), 209-216.

Huang, Z., \& Li, S. X. (2001). Co-op advertising models in manufacturer-retailer supply chains: A game theory approach. European journal of operational research, 135(3), 527-544.

Ji, J., Zhang, Z., \& Yang, L. (2017). Comparisons of initial carbon allowance allocation rules in an $\mathrm{O} 2 \mathrm{O}$ retail supply chain with the cap-and-trade regulation. International Journal of Production Economics, 187, 68-84.

Ji, T., Xu, X., Yan, X., \& Yu, Y. (2020). The production decisions and cap setting with wholesale price and revenue sharing contracts under cap-and-trade regulation. International Journal of Production Research, 58(1), 128-147.

Karray, S., Martin-Herran, G., \& Sigué, S. P. (2017). Cooperative advertising for competing manufacturers: The impact of long-term promotional effects. International Journal of Production Economics, 184, 21-32.

Karray, S. (2015). Cooperative promotions in the distribution channel. Omega, 51, 49-58.

Kleindorfer, P. R., \& Saad, G. H. (2005). Managing disruption risks in supply chains. Production and operations management, 14(1), 53-68.

Li, G., Zheng, H., Ji, X., \& Li, H. (2018). Game theoretical analysis of firms' operational low-carbon strategy under various cap-and-trade mechanisms. Journal of cleaner production, 197, 124-133.

Lin H., Shao P. (2014). Research on Enterprise Network Advertising Investment Strategy based on Internet Environment . Chinese Management Science, 22(2):65-74.

Lou, W., \& Ma, J. (2018). Complexity of sales effort and carbon emission reduction effort in a two-parallel household appliance supply chain model. Applied Mathematical Modelling, 64, 398-425.

Ma, J., Hou, Y., Yang, W., \& Tian, Y. (2020). A time-based pricing game in a competitive vehicle market regarding the intervention of carbon emission reduction. Energy Policy, 142, 111440.

Ma, J., \& Sun, L. (2017). Complexity analysis about nonlinear mixed oligopolies game based on production cooperation. IEEE Transactions on Control Systems Technology, 26(4), 1532-1539.

Ma, J., \& Xie, L. (2016). Study on the complexity pricing game and coordination of the duopoly air conditioner market with disturbance demand. Communications in Nonlinear Science and Numerical Simulation, 32, 99-113.

Ma, J., \& Xie, L. (2016). The comparison and complex analysis on dual-channel supply chain under different channel power structures and uncertain demand. Nonlinear Dynamics, 83(3), 1379-1393.

Ma, J., \& Sun, L. (2017). Complexity analysis about nonlinear mixed oligopolies game based on production cooperation. IEEE Transactions on Control Systems 

Technology, 26(4), 1532-1539.

Ma, J., \& Wu, F. (2014). The application and complexity analysis about a high-dimension discrete dynamical system based on heterogeneous triopoly game with multi-product. Nonlinear Dynamics, 77(3), 781-792.

Meng, J., Yang, Z., Liu, L., Cui, F., \& Jiang, Y. (2019). The in-situ growth of zinc-aluminum hydrotalcite on hollow carbon spheres and its application as anode material with long cycle life for zinc-nickel secondary battery. Journal of Alloys and Compounds, 809, 151842.

Qian, X., Chan, F. T., Zhang, J., Yin, M., \& Zhang, Q. (2020). Channel coordination of a two-echelon sustainable supply chain with a fair-minded retailer under cap-and-trade regulation. Journal of Cleaner Production, 244, 118715.

Tong, W., Mu, D., Zhao, F., Mendis, G. P., \& Sutherland, J. W. (2019). The impact of cap-and-trade mechanism and consumers' environmental preferences on a retailer-led supply Chain. Resources, Conservation and Recycling, 142, 88-100.

Wang, M., Zhao, L., \& Herty, M. (2018). Modelling carbon trading and refrigerated logistics services within a fresh food supply chain under carbon cap-and-trade regulation. International Journal of Production Research, 56(12), 4207-4225.

Xiao, T., Qi, X., \& Yu, G. (2007). Coordination of supply chain after demand disruptions when retailers compete. International Journal of Production Economics, 109(1-2), 162-179.

Xie, J., Liang, L., Liu, L., \& Ieromonachou, P. (2017). Coordination contracts of dual-channel with cooperation advertising in closed-loop supply chains. International Journal of Production Economics, 183, 528-538.

Xie, L., Ma, J., \& Goh, M. (2021). Supply chain coordination in the presence of uncertain yield and demand. International Journal of Production Research, 59(14), 4342-4358.

$\mathrm{Xu}, \mathrm{T}$, \& Ma, J. (2021). Feed-in tariff or tax-rebate regulation? Dynamic decision model for the solar photovoltaic supply chain. Applied Mathematical Modelling, 89, 1106-1123.

Xu, X., He, P., Xu, H., \& Zhang, Q. (2017). Supply chain coordination with green technology under cap-and-trade regulation. International Journal of Production Economics, 183, 433-442.

Yang, L., Zhang, Q., \& Ji, J. (2017). Pricing and carbon emission reduction decisions in supply chains with vertical and horizontal cooperation. International Journal of Production Economics, 191, 286-297.

Zhan, X., Ma, J., Li, Y., \& Zhu, L. (2019). Design and coordination for multi-channel recycling of oligopoly under the carbon tax mechanism. Journal of cleaner production, 223, 413-423.

Zhang, R., Liu, B., \& Wang, W. (2012). Pricing decisions in a dual channels system with different power structures. Economic Modelling, 29(2), 523-533.

Zhang, S., Wang, C., \& Yu, C. (2019). The evolutionary game analysis and simulation with system dynamics of manufacturer's emissions abatement behavior under cap-and-trade regulation. Applied Mathematics and Computation, 355, 343-355.

Zhou, Y. W., Li, J., \& Zhong, Y. (2018). Cooperative advertising and ordering policies 
904

905

906

907

908

909

910 in a two-echelon supply chain with risk-averse agents. Omega, 75, 97-117.

Zhu, M., Li, X., Zhu, L., Zhan, X. etc. (2021). Dynamic Evolutionary Games and Coordination of Multiple Recycling Channels considering Online Recovery Platform. Discrete Dynamics in Nature and Society, 2021.

Meihong Zhu, Xiao Li, Chengjin Liu et al., "Research on Pricing and Risk Control of a Zn-Ni battery Industry Chain based on Low Carbon Background," Environmental Science and Pollution Research, vol.8, 2021. 